\title{
Competence to thrive: resilience as an indicator of positive health and positive welfare in animals
}

\author{
Ian G. Colditz ${ }^{\mathrm{A}}$ \\ ACorresponding author. Email: ian.colditz@csiro.au \\ Running head: Competence to thrive
}

\begin{abstract}
A capacity for an animal to maintain or regain healthy functioning in the face of environmental disturbances is recognised as resilience. For the individual animal, dynamic properties of the trajectory of performance traits (e.g. daily milk yield), periodicity of physiological and behavioural variables (e.g. body temperature) and complexity of biological functions (e.g. behavioural repertoire) can provide measures of its resilience. These measures provide a view of the individual's attempts to cope physically (and emotionally) with its non-shared micro-environment. The concept of resilience is examined as a multifaceted attribute that is hidden from direct measurement. The challenges for establishing relationships between general resilience and contextspecific resilience such as disease resilience are explored by comparison with the multifaceted construct of temperament (personality). Lower variance in deviations from performance trajectories and stronger periodicity in rhythmic physiological and behavioural variables are favourably associated with health and longevity in several livestock species. In humans, wellbeing is associated with health outcomes, and biomarkers of health are more strongly associated with eudaimonic than hedonic wellbeing. The psychological state of eudaimonia is associated with the capacity to express agency, function well, fulfil biological potential and express environmental mastery. The need for indicators of eudaimonia in animals has been suggested previously. Links between environmental mastery and the capacity to develop and express physiological, immune, behavioural, cognitive and affective competencies are examined. It is suggested that longitudinal data on individual animals can provide a precision welfare indicator of eudaimonic positive welfare. In this view, positive welfare entails both eudaimonic and hedonic aspects of wellbeing, neither of which is alone sufficient to describe nor to maximise positive welfare. Cumulative scores of resilience may have utility for assessing the lifetime welfare experience of the individual and when summed at the farm level may provide a metric for benchmarking welfare performance. Breeding for resilience selects for normativity of biological functions assessed against the individual animal's own baseline of inherited and developmentally acquired potential. This differs from current approaches to selection for production which aim to maximise production or production efficiency benchmarked against the group mean. Biological costs and trade-offs associated with selection for resilience require further research.
\end{abstract}

Additional key words: eudaimonia, hedonia, positive welfare, positive health, latent construct, quality of life, homeorhesis, allostasis, homeostasis, stress, temperament, personality, construct validation, affect, valence, arousal, biorhythms, behavioural complexity, precision welfare assessment

\section{Summary text}

New phenotyping methods are revealing resilience of animals to fluctuations in their environment. Resilience describes normativity of physiological, behavioural and production performance 
irrespective of actual production level and provides insight into the animal's experience of its personal environment. An ability of the animal to realise its potential is built on inherited and acquired competences that confer environmental mastery. Competence to cope minimises harms. Competence to thrive recognized as resilience indicates eudaimonic wellbeing and supports positive health and positive welfare outcomes.

\section{Introduction}

Since the emergence of animal welfare in the 1960s as an issue of strong public concern, welfare has been considered in broad terms to include the physical and mental wellbeing of the animal. The Brambell report into the welfare of intensively housed livestock (Brambell 1965, page 9) suggested that "Any attempt to evaluate welfare ... must take into account the scientific evidence available concerning the feelings of animals that can be derived from their structure and functions and also from their behaviour." Many public submissions to the Brambell committee considered that growth rate of meat animals and egg production by hens were "the only reliable objective measures of their welfare" (Brambell 1965). Nonetheless, the committee concluded that "Growth ... can be a pathological symptom, although it is more often a mark of health. Growth rate and condition ... together are a better guide ... but are not inconsistent with periods of acute, but transitory, physical or mental suffering... A principal cause of suffering in animals ... is disease." (page 11). Reflecting this sentiment, Hurnik and Lehman (1988) noted that production traits such as milk yield that underpin the commercial value of a farm animal represent only one aspect of its biological functioning. Normality of production, reproduction, immune function and behaviour together with the presence of physiological and behavioural indicators of pleasure were all considered necessary for an animal to possess good welfare (Broom 1996). Failure to express these activities was a sign the animal was coping poorly with its environment and in a state of poor welfare (Broom 1996; Mellor 2016). Misgivings about production as a singular measure of welfare (e.g. Duncan and Dawkins 1983; Broom 1986) were reinforced by the observation of many undesirable side-effects on health, immune function, metabolic functions and reproduction that accompany genetic selection for production efficiency in pigs, chickens and dairy cows (Rauw et al. 1998). Selection for productivity, these authors suggested, reduces allocation of resources to fitness functions in the animal and diminishes its capacity to maintain a homeostatic balance and to cope with environmental challenges (Rauw et al. 1998). As described in more detail below, recent years have seen a resurgence in the use of production variables to assess the capacity of animals to cope with environmental perturbations. This trend has been enabled by large datasets containing high frequency records of behavioural, physiological and production variables of individual animals (e.g. Neethirajan et al. 2017; Brito et al. 2020; Sun et al. 2021). Assessments at the level of the individual animal of dynamic properties of the trajectory of performance traits such as milk yield, periodicity of physiological and behavioural variables, and complexity of biological functions such as behavioural repertoires are being interpreted as 1 ) evidence of resilience to environmental perturbations, 2) an indicator of welfare, and 3) an avenue for improving health and welfare through genetic selection (Scheibe et al. 1999; Colditz and Hine 2016; Berghof et al. 2018; Nunes Marsiglio Sarout et al. 2018; 
Van Dixhoorn et al. 2018; lung et al. 2019; Bai and Plastow 2022). One aim of this review is to examine the merits of these inferences.

The concept of animal welfare has been consolidated to a tripartite model that encompasses three broad perspectives: biological function, natural living, and affective state (Fraser et al. 1997; Fraser 2008; Mellor 2016), although limitations of the model are recognized (Weary and Robbins 2019). Welfare has been described in the following terms: "that animals should feel well by being free from prolonged or intense fear, pain and other unpleasant states, and by experiencing normal pleasures; that animals should function well in the sense of satisfactory health, growth and normal behavioral and physiological functioning; and that animals should lead natural lives through the development and use of their natural adaptations" (italics in original, Fraser 2008). These perspectives are represented in the principles of the Five Freedoms (Webster 2016), in the Five Domains framework (Mellor 2017) and in the dictum "health and what animals want" (Dawkins 2021), and are implemented for assessment of welfare through programs such as WelfareQuality ${ }^{\circledR}$ (Botreau et al. 2007). Animal-based measures play a prominent role in welfare assessments and new methods for measuring biological function, natural living and affective state are being developed to complement theoretical and evidenced-based advances in understanding what animals are, what they can be, and how they function (Mellor 2016; Duncan 2020). Advances in the concept of animal resilience and new methods for its measurement are a part of this dynamic (Hine et al. 2015; Colditz and Hine 2016; Friggens et al. 2017; Berghof et al. 2018; Van Dixhoorn et al. 2018; Brito et al. 2020; Abdelkrim et al. 2021; Bai and Plastow 2022).

Given past shortcomings of production as a measure of welfare, what can newer measures of biological function reveal about the welfare state of production animals? This review examines the conceptual relationship between resilience, health and welfare, and the contribution that measures of resilience based on production, physiology and behavioural data may be able to make to improving farm animal welfare. The review begins by examining recent research on resilience in production animals and methods for its measurement based on analysis of trajectories in production, physiological and behavioural performance. Persistence of performance trajectories, biorhythms and functional complexity, as opposed to change and adaptation in the face of environmental fluctuations, is described as a normative process grounded in homeorhetic physiological regulation. The relationships between beneficial health and welfare outcomes associated with measures of resilience and the concepts of eudaimonic and hedonic wellbeing are then examined. It is suggested that inherited and developmentally aquired attributes of the animal that contribute to resilience not only minimise harms but also confer functional competence to thrive that can provide eudaimonic wellbeing, positive health and positive welfare outcomes to the animal. A framework is presented that links resilience and the eudaimonic dimension of wellbeing with the duration of affective experience. Eudaimonic wellbeing is described as the bridge that links animal welfare science with quantitiative studies on resilience phenotypes.

\section{Resilience}

Animals vary in their capacity to cope with variation in their environment (Broom 1996); however, variation in the environment is not intrinsically bad for animals. Indeed, all organisms strive to 
predict and control their environments and to synchronise their activities with variations in environmental conditions (Jensen and Toates 1997; Scheibe et al. 1999; Lyon 2015; Bruineberg et al. 2018; Colditz 2018; Kristiansen and Fernö 2020). In this view, environmental variation does not necessarily constitute an environmental challenge, perturbation or disturbance; rather it is environmental variation that cannot be predicted or controlled that poses a challenge to the animal (Jensen and Toates 1997; Lee et al. 2018; Kristiansen and Fernö 2020). A capacity for animals to be minimally affected by environmental disturbances or to rapidly recover from them is recognised as resilience (Hine et al. 2015; Tedeschi et al. 2015; Colditz and Hine 2016; Friggens et al. 2017; Berghof et al. 2018; Van Dixhoorn et al. 2018; Bai and Plastow 2022).

Resilience in livestock has been described in many contexts. A type of resilience appears to have been first recognized in farm animals as a distinction between resistance to infestation and resistance to the effects of infestation of sheep with the nematode parasite Haemonchus contortus (Clunies Ross 1932). Resilience has been assessed in the context of nematode parasite infection (Albers et al. 1987; Bisset and Morris 1996; Kelly et al. 2013), microbial infection (Mulder and Rashidi 2017; Putz et al. 2019; Bai and Plastow 2022) high or low temperature exposure (Mengistu et al. 2017; Sánchez-Molano et al. 2020; Tsartsianidou et al. 2021), diet (Steel 2003), feed shortage (Marla et al. 2004), weaning (Hine et al. 2019; Revilla et al. 2019), routine management within the production environment (Meyer and Colditz 2015; Elgersma et al. 2018; Nunes Marsiglio Sarout et al. 2018; Nguyen-Ba et al. 2020; Poppe et al. 2020; Poppe et al. 2021b; Sun et al. 2021; Bai and Plastow 2022), and the transition period in the dairy cow (Van Dixhoorn et al. 2018) amongst other contexts (e.g. Bushby et al. 2018; Brito et al. 2020).

Historically, infectious diseases have attracted the strongest attention in studies of resilience in livestock. Resilience to infection is usually described as the relative level of production at a given level of infection and can be identified by comparison among animals or within an animal over time (Bishop 2012; Knap and Doeschl-Wilson 2020; Bai and Plastow 2022). It is distinguished from resistance which is described as the relative level of infection an animal develops at a given level of pathogen exposure. Tolerance to infection is described as the sensitivity of production to a change in the level of infection (Simms 2000; Bishop 2012; Knap and Doeschl-Wilson 2020; Bai and Plastow 2022). Knap and Doeschl-Wilson (2020) suggest that disease resilience can be modelled as a reaction norm of production on pathogen load, given known levels of resistance and tolerance.

Epidemiological characteristics of a disease such as the occurrence of super-spreaders can have a strong influence on exposure of herd-mates to a pathogen (Eady et al. 2003). As a consequence, disease resilience of a population is a property of the group that is more than the sum of the disease resilience of its members (Doeschl-Wilson et al. 2021). This well-developed model of disease resilience provides a basis for examining the concepts of context-specific and general resilience below.

\section{Measuring resilience}

Many of the studies of resilience described above are based on repeated measurement of variables within an individual animal across a period of time. Statistical measures of the dynamic properties of such longitudinal data have been used to quantify deviation from a prior trajectory or periodic 
pattern. Examples include variance, autocorrelation, skewness and periodicity (Scheibe et al. 1999; Nunes Marsiglio Sarout et al. 2018; Van Dixhoorn et al. 2018; Berghof et al. 2019; lung et al. 2019; Poppe et al. 2020) although other statistical measures of deviation and synchronisation of periodicity have been used (Scheibe et al. 1999; Putz et al. 2019; Nguyen-Ba et al. 2020). The narrative description of resilience and the statistical methods for its estimation are normative models of biological function. Thus, the trajectory of a performance trait, or the periodic behaviour of a variable is theorised or empirically estimated to be a smooth function (e.g. Nguyen-Ba et al. 2020; Abdelkrim et al. 2021). By focusing on resilience as a desirable characteristic of the animal, conformity to a normal trajectory is valued by the scientist above deviation or change in a trajectory that may represent reprioritisation of the use of resources by the animal. In this conceptualisation, the resilient animal is understood to defend expression of a trait or biological function against environmental perturbations (Baffy and Loscalzo 2014). Is this normative model of biological function in accord with models of physiological regulation and stress? Before addressing this question, some other points on measuring resilience are noteworthy.

Firstly, in most assessments, the baseline from which deviations are estimated for quantifying resilience is the performance trajectory of the individual animal. In idealised form, this approach measures the success of the individual in achieving its inherited and developmentally acquired potential for expression of a performance trait, and contrasts with assessment of production which is measured against performance of other individuals. Thus, whereas productivity is a measure of absolute production or production efficiency, resilience is a measure of uniformity of biological function that may be independent of the actual level of production performance. In practical terms, resilience has been found to be a different trait to production (Elgersma et al. 2018) and in dairy cows is negatively correlated with milk yield (higher yielding cows have lower resilience) (Poppe et al. 2020).

Secondly, an alternative approach to measuring resilience has been used by Hine and colleagues (Aleri et al. 2019; Hine et al. 2019; Hine et al. 2021; Hine et al. 2022). These authors have measured the strength of the immune response during the stress of routine husbandry practices such as weaning of beef calves and lambs bred and raised in a pasture-based production system. This approach measures the absolute level of performance of the immune system, termed immune competence, under stress rather than characteristics of response kinetics (Hine et al. 2019; Hine et al. 2022) and complements a large body of work on associations between immune competence and disease outcomes in livestock (for reviews see Wilkie and Mallard 1999; Hine et al. 2015; Mallard et al. 2015; König and May 2019; Bai and Plastow 2022). Immune competence measured in dairy heifers during routine husbandry is negatively correlated with cortisol responses (Aleri et al. 2019) and thus immune competence may be an indicator of resilience. In support of this conclusion is the observation that protective host responses to heat stress are stronger in cows with high immune competence (Cartwright et al. 2021; Cartwright et al. 2022).

Thirdly, structure and complexity within the daily organization of behaviour has been analysed as a measure of resilience to environmental stressors such as a barren environment in mice (Freund et al. 2013) or feed shortage in chickens (Maria et al. 2004). The salient feature of these studies is that behavioural complexity at the individual and the group level is reduced in stressful conditions. Loss 
of complexity is also a hallmark of physiological activities under stressful conditions (Asher et al. 2009; Baffy and Loscalzo 2014). A review of statistical methods for analysis of behavioural complexity as potential indicators of resilience is provided by Asher et al. (2009).

Finally, detailed accounts of methods for analysis of dynamic indicators of resilience are provided by Baffy and Loscalzo (2014), Scheffer et al. (2018), Scheibe et al. (1999) and Nunes Marsiglio Sarout et al. (2018). For a critique of dynamic indicators as measures of resilience see Knap and DoeschlWilson (2020). Dynamic indicators of resilience are based on resilience theory and are described as generic indicators of systemic resilience that can provide whole-of-animal indicators of the animal's state in the face of environmental perturbations (Scheffer et al. 2018).

\section{Physiological regulation of trait expression}

What do models of physiological regulation tell us about the trajectory of performance traits? Briefly, the development and expression of morphological and biological functions during ontogeny and later life exhibiting varying degrees of robustness and plasticity in the face of environmental variation. The physiological processes supporting robustness and plasticity are respectively termed homeorhesis and allostasis. Homeorhesis describes the activity of physiological intermediaries such as neuroendocrine and peripheral tissue-derived hormones in guiding the transition of the animal to a new physiological state such as lactation, and then maintaining and buffering the state against environmental fluctuations (Waddington 1942; Bauman and Currie 1980). Homeorhesis is a wholeof-animal modulation of physiological activities in support of a physiological state or performance trajectory (for review see Colditz 2020). The homeorhetic regulatory environment modulates sensitivity of tissues to homeostatic signals such as insulin and changes the range within which variables such as blood glucose are regulated (Bell and Bauman 1997). Homeorhesis constrains (canalizes) expression of form and function along trajectories that exhibit resistance to disturbance by environmental variation. This buffering of a trajectory against environmental fluctuations is seen in many contexts in livestock including pregnancy (Greenwood et al. 2017) and compensatory growth (Wilson and Osbourn 1960). Nonetheless, many biological functions can adapt and exhibit plasticity in the face of environmental change and express a modified level of performance (Goldstein and Kopin 2007; Baffy and Loscalzo 2014). Physiological regulation of plasticity has been termed allostasis (Sterling and Eyer 1988; Romero et al. 2009; Koolhaas et al. 2011), although the term is also used to describe the short-term anticipatory regulation of physiological functions within their normal homeostatic range (Schulkin and Sterling 2019). As with homeorhesis, the influence of allostasis on morphology and sensitivity of tissues to homeostatic signals can change the range and response characteristics of homeostatic variables (Goldstein and Kopin 2007; Romero et al. 2009; Koolhaas et al. 2011). The rapid return to a homeorhetic trajectory of performance is likely to arise from homeostatic process operating within the homeostatic range established by homeorhetic regulation (Bauman 2000; Baffy and Loscalzo 2014; Colditz 2020; Friggens et al. 2022).

It is evident from the preceding discussion that homeorhesis and allostasis are abstract conceptual models of physiological processes that are used to account for phenomena of persistence or variability in trait expression and biological function in the face of environmental variation. Many biotic and abiotic factors contribute to environment variation, and environmental conditions can 
vary over long and short timescales. The spatial scale of environmental variation can extend from the individual animal (micro-environment) to the level of the cohort, farm, or geographic region (macro-environment) (Strandberg 2009). Heritable variation in the stability of trait expression may differ between micro- and macro-environmental scales (Madsen et al. 2021). Nonetheless, a degree of arbitrariness exists in drawing a distinction between robustness (macro-environmental scale) and resilience (micro-environmental scale) (Friggens et al. 2017; Friggens et al. 2022). Plasticity is also a heritable trait (Strandberg 2009; Santana et al. 2013). Whereas resilience describes a normative pattern of trait expression, plasticity describes a deviation from this norm towards an altered (and sometimes adaptive) pattern (Baffy and Loscalzo 2014). Selection for plasticity would value flexibility over uniformity. It is noteworthy that a capacity to return to a prior pattern of performance following an environmental perturbation is described as adaptive plasticity by some authors (e.g. Nunes Marsiglio Sarout et al. 2018 and references therein). Is resilience a desirable characteristic to breed for? Beneficial long-term outcomes associated with resilience could provide some justification.

\section{Consequences of resilience}

A strong focus of studies on resilience measures has been placed on associations with subsequent health, fitness and production outcomes. Favourable associations have been identified between resilience measures and desirable longer-term outcomes in a number of contexts. Measures of deviation in daily milk yield of dairy cows were favourably genetically correlated with better udder health, longevity of the cow within the herd, fertility, body condition score and dry matter intake, and reduced susceptibility to ketosis (Poppe et al. 2020). Characteristics of the milk yield curve and behavioural activity in the first lactation were associated with longevity and reproductive performance (Adriaens et al. 2020). Variability in daily feed intake and feeding duration were genetically correlated with mortality and treatment rates in pigs exposed to natural disease challenge (Putz et al. 2019). Using a measure of the capacity of beef steer calves to mount an immune response to vaccination during the stress of weaning while confined in outdoor cattle yards, Hine et al. (2021) found a favourable association between high immune competence and low mortality during subsequent finishing in a commercial feedlot. Immune competence measured during the stress of yard weaning in lambs was favourably genetically correlated with the incidence of fly strike, faecal soiling of the breech (dag score), faecal worm egg count, and a composite fitness measure (Hine et al. 2022). Deviations from normality in average eating time, daily ear temperature dynamics and daily behavioural activity in late pregnancy were predictive of a suite of health deficits in early lactation in dairy cows (Van Dixhoorn et al. 2018). There are many additional studies on beneficial outcomes related to resilience in livestock reported in the literature.

Gradual loss of resilience may be an intrinsic characteristic of aging and senescence. Analysis of the dynamic characteristics of serial white blood cell counts and daily activity assessed by wearable devices in large datasets in humans reveal an association between resilience and longevity. Past an age in the mid-40s, the magnitude of deviations and duration of recovery time in both variables increased in proportion to age, which the authors interpreted as indicating physiological resilience declines with increasing age as an intrinsic process of senescence in a manner that sets an upper limit on lifespan (Pyrkov et al. 2021). 
The individual resilience score for dairy cows based on daily milk yield variance, shape of the lactation curve and behavioural activity, when averaged at the farm level was found to differ substantially between farms (Adriaens et al. 2020; Poppe et al. 2021a). Farms with poor resilience scores tended to have a higher proportion of cows with rumen acidosis, higher somatic cell count, lower fat content, longer calving interval, lower survival to second lactation, larger herd size, lower lactose content, and higher production (Poppe et al. 2021a). The results illustrate the potential for resilience scores calculated at the farm level to provide a measure for benchmarking welfare performance between farms (von Keyserlingk et al. 2012; Colditz et al. 2014).

Together these findings lend support to resilience being a desirable attribute of the animal both for its short-term benefits manifest as uniformity of daily performance and for its association with longer term beneficial outcomes. A recurrent question raised by such favourable associations is the extent to which resilience is context specific or is a characteristic of animals that is expressed as a general trait in the face of a diversity of environmental challenges. The question leads to a consideration of resilience as a conceptual construct.

\section{Resilience as a conceptual construct}

Behind field studies of many biological phenomena are abstract theoretical models of the relationships that exist between measured variables and underlying characteristics of the animal. These models constitute conceptual constructs that are not always able to be directly observed (Scott et al. 2001). Friggens et al. (2022) suggest that the concept of resilience in livestock is just such a multi-faceted construct and that it is obscured from direct measurement. Tools used to quantify resilience, the authors suggest, can reveal aspects of the underlying construct of resilience, while assessment of the cumulative longer-term consequences of resilience such as health and fitness outcomes are needed to provide external validation of the construct. This insightful observation helps establish a framework for refinement of the conceptual construct of resilience and for its implementation through measurement tools for use in welfare assessment and for phenotyping animals for genetic analyses.

Many concepts in biology are abstract multi-faceted constructs that cannot be directly measured. To quantify the construct, proxy variables can be measured from which a value or state of the hidden or latent trait is inferred. Examples include unobservable constructs such as intelligence, personality and quality of life (Scott et al. 2001). Detailed methods have been established in psychometrics for developing and validating constructs, for developing measurement instruments such as scoring scales for assessing the individual, and for analysing scores. For examples of application of these methods to development of measurement instruments for assessing health-related quality of life in animals see Reid et al. (2022) and personality (temperament) in animals see (Carter et al. 2013).

An important component of a conceptual construct is the relationship that is theorised to occur between the measured variables and the underlying character or latent trait of the animal described by the construct. Several types of relationship are theorised. Firstly, the measured variables can be indicators that reflect aspects of the underlying construct but are neither caused by nor do they causally influence the construct (Figure 1a). Health-related quality of life is an example of this class 
of conceptual construct (Reid et al. 2022). Secondly, when a causal relationship is theorised to exist between the measured variables and the hidden construct, causation is theorised to take one of at least three forms: 1 ) the measured variables cause the latent trait (Figure 1b), 2) the measured variables are caused by the latent trait (Figure 1c), or 3) the measured variables interact in a network that manifests the latent trait as an emergent system property of the network - the latent trait is not considered to exist as an entity that is separate from interactions between the network variables (Guyon et al. 2017) (Figure 1d). For a detailed account of the application of these three models to theories of emotions (appraisal, constructionist, affect-program) in humans see Lange et al. (2020). In simplified terms, for the example of the emotion of fear in animals, in causal model one, an increase in heart rate would be part of a suite of physiological and behavioural changes that cause occurrence of the emotion of fear. In model 2 , occurrence of the emotion of fear would cause a suite of physiological and behavioural changes including increase in heart rate. In model 3 , changes in a suite of physiological and behavioural variables occurring in a particular situation or context evince a system property within the network of interacting variables that is, in and of itself, an instance of fear (Figure 1d). Network theory (model 3) has recently been applied to animal welfare (Rowland et al. 2021) and resilience (Scheffer et al. 2018). In this view, attributes like fear and temperament (and resilience as discussed below) are not substantive entities that can act like an extra hand to manipulate yet other entities such as cognition, immune function, behaviour or energy metabolism. Rather, attributes like fear and temperament are distributed properties realised through activity within sub-cellular, cellular, organ and whole-body processes (Baffy and Loscalzo 2014; Guyon et al. 2017; Scheffer et al. 2018; Colditz 2021).

For hidden constructs like health-related quality of life, the definition of the construct is considered to be independent of the variables. Thus, scores of energy, happiness, comfort and calmness that are used in the assessment of health-related quality of life in animals reveal aspects of the construct but do not themselves define health-related quality of life (Reid et al. 2022) (Figure 1a). In contrast, where a causal relationship lies between the construct and the measured variables, the variables often provide at least a partial definition of the construct (Fayers and Hand 2002). For example, the concept of glucose homeostasis, which in broad conceptualisation is a dynamic whole-of-animal state (Baffy and Loscalzo 2014), can be operationalised by proximate measurements of blood concentrations of glucose, insulin, and glucagon (Modell et al. 2015). In this minimal model, glucose homeostasis is defined as the balance between the measured variables glucose, insulin and glucagon. Yet, moving beyond these initial measures, the construct can be further refined as an outcome state arising from the dynamics of expression levels of the various glucose receptor types on target tissues, intracellular enzyme kinetics, glycogen reserves, autonomic tone, liver health, pancreatic function and more (Bell and Bauman 1997). In this manner, the construct can be defined at various levels of refinement by the variables that are measured.

A further characteristic of unobservable constructs is the lack of an external gold standard against which to validate that the measured variables give a true report of the status of the hidden trait (Fayers and Hand 2002). It is a common conclusion that assessment of the welfare state of an animal lacks such an external gold standard (Scott et al. 2001). This statement differs from use of the term gold standard to describe a benchmark or threshold of performance against a suite of indicators that is deemed to constitute an acceptable or optimal (gold standard) level of welfare (for 
examples of this important and entirely valid usage of the term see Mellor and Stafford (2001) and Sandgren et al. (2009)). The relationship between the measured variables and the unobservable construct remains a theoretical model that can be iteratively refined and validated through welldescribed procedures for construct validation (Fayers and Hand 2002; Carter et al. 2013). For examples of the application of methods for construct validation to human-animal relationships see Waiblinger et al. (2006) and for animal personality see Carter et al. (2013).

Many measurements made on animals can be validated against external gold standards. For example, measurement of milk yield of goats can be validated against volumetric or gravimetric standards, and data on daily milk yield over the course of a lactation can be used to generate an empirical model of the lactation curve of the individual animal (for an example see Abdelkrim et al. 2021). Complementing the empirical model can be a suite of more abstract concepts, some of which may be less accessible for direct measurement than the expressed phenotype of daily milk yield. A plausible hierarchy of progressively more abstract concepts in this example could include the propositions that: 1) a performance trait, such as a lactation curve, is expressed as an unperturbed dynamic trajectory across time in an ideal environment; 2) failure of an animal to cope with environmental perturbations can compromise expression of a performance trait like daily milk yield as an unperturbed dynamic trajectory; and 3) reiterating Broom (1996), the state of the animal as it attempts to cope with its environment is a fundamental aspect of its welfare that can be partially revealed through analysis of the trajectory of a performance trait. The hierarchy provides a transition from an empirical model of an expressed production trait that has been validated against an external standard to a hidden construct of welfare that lacks direct concordance with a gold standard.

Many of the "big ideas" in biology such as consciousness, temperament, emotion, affective valence, fitness, homeostasis, homeorhesis, allostasis, stress, sustainability, health and welfare share with resilience this character of being multifaceted constructs that can be partially revealed from various perspectives through application of assessment tools and by measurement of proximate mechanistic processes. Such concepts often appeal to an intuitive understanding grounded in folk wisdom and are used in a manner described in semiotics as floating signifiers. One approach to constraining abstract constructs is to define the construct as being limited to the variables that are measured for its estimation as illustrated for disease resilience (e.g. Knap and Doeschl-Wilson 2020; Bai and Plastow 2022) and for homeostasis (e.g. Modell et al. 2015). It follows that ongoing development, refinement and validation of the concepts and their empirical relation to biological outcomes is of utmost importance. Nonetheless, theoretical and empirical development can proceed simultaneously, and resolution of the conceptual construct is not a prerequisite for application of a version of the construct in practical studies (Dawkins 2021).

The diversity of hypotheses that align with the concept of stress helps illustrate this point. In a review of the literature on studies examining the role of stress in behavioural and physiological processes involved in life-history trade-offs, developmental transitions, health, and survival, Harris (2020) identified 131 hypothesis that propose a role for stress in these outcomes. While many of the hypotheses shared similarities and made similar predictions, the diversity of hypotheses illustrates a lack of harmonization and consolidation of the concepts both at a theoretical level and when they 
are tested in experimental studies. Many of the hypotheses are highly cited within the animal welfare literature, yet none of the hypotheses on the role of stress in animal welfare were captured in the literature review or represented in the classification framework developed by the author. Nonetheless, the lack of conceptual clarity as to what stress is, how it operates, and the consequences of its occurrence does not diminish the central importance of the conceptualization and measurement of stress to understanding animal welfare.

From this background it follows that the concept of resilience is likely to be used in the literature at various degrees of conceptual abstraction and refinement. This provides a tone of caution to the search for a simple unified concept of resilience.

\section{Personality as an analogy for resilience}

What might a multi-faceted construct of resilience look like? The relationship between the different components of a multifaceted construct can be difficult to resolve. For resilience, a central question is whether there is a unitary construct that can manifest as general resilience across a diversity of environmental contexts including infectious disease, husbandry stressors, climatic variability, social stress and so on, or whether resilience in each context is a separate trait as suggested by Llonch et al. (2020). Studies on defined phenotypes in defined environmental contexts like the examples described above can provide pragmatic answers to whether context-specific resilience has utility for assessing welfare and for breeding. Nonetheless, a number of authors suggest a more general character of the animal may exist that can confer resilience across a diversity of environmental contexts thereby providing a range of beneficial outcomes (e.g. Hine et al. 2015; Colditz and Hine 2016; Scheffer et al. 2018; Putz et al. 2019; Harlizius et al. 2020; Sun et al. 2021). The question gains importance because of potential implications for identifying the context in which to measure the general resilience phenotype and the variables suitable for its quantification.

Personality provides an example of a multifaceted construct of importance in animal science that may help illustrate how resilience as a unitary construct may operate across multiple dimensions and contexts. All animals are considered to have a "temperament" or "personality". In abstract form, temperament/personality is often described as having five aspects, exploration, activity, aggressiveness, sociability, and boldness which are revealed through persistent patterns of behaviour that are repeated across contexts or across time within a context (Réale et al. 2007; Carter et al. 2013; Finkemeier et al. 2018). Importantly, the relative level of expression of each aspect of temperament can differ consistently between individuals and covaries with physiological, immunological and performance differences between individuals (Careau and Garland Jr 2012). The relationships between temperament and physiological and immunological functions and performance have been interpreted to support a conceptual model of temperament as an attribute of the animal that manifests in, and is operationally defined through behaviour alone, with the underlying latent variable temperament exerting a causal influence on other functions such as immune and metabolic activities. A large number of tests such as flight speed in cattle have been developed to measure aspects of temperament (Burrow 1997). Genetic and phenotypic associations of a measured trait such as flight speed with productivity, meat quality, health and reproductive performance can be utilised in animal management and breeding programs (Haskell et al. 2014). In 
contrast to assessment of one aspect of temperament via a single test, performance of animals in a suite of tests such as judgement bias and attention bias tests in cattle can be analysed to estimate the relative contribution of various aspects of temperament to the behaviours measured in each test (Kremer et al. 2021). In this example, the authors concluded that differences between individuals in activity, fearfulness (the opposite of boldness) and sociability modulated their activity in the tests. Such studies contribute to the ongoing refinement of the general concept of temperament and methods for its assessment, and enable application of the general concept and the specific tests to questions such as the influence of affective state on performance in the tests and conversely, the utility of the tests to measure affective state when performance is conditioned on temperament scores (Kremer et al. 2021). Ongoing interpretation of the relationships between behaviours, physiology, immune function and performance support refinement of the causal model of temperament to the concept of temperament as a distributed network property embedded in physiological, immunological and performance functions as well as in behaviour (Colditz 2021): a model no doubt requiring further refinement. The distributed/embedded model suggests that measurement of the underlying temperament trait might be improved by measurements made on each dimension rather than by measurements solely of behaviour, a proposition supported by studies on body temperature and blood lactate as predictors of temperament in cattle (Williams et al. 2019). The example of temperament illustrates that the core concept of resilience could exhibit various aspects which individuals consistently express to varying extents in different contexts such as disease, social and climatic challenges, and that measurement of multiple aspects could improve triangulation of the underlying conceptual construct. This conceptual model of resilience aligns closely with that proposed by Friggens et al. (2022). A challenge for advancing this field of research is to tolerate ambiguity in the conceptual construct while specific measures of "resilience" are refined through empirical studies.

\section{Implications for health and welfare}

The biological links between a capacity to be minimally affected by short-term fluctuations in the environment, as evidenced by performance trajectories, biorhythms and functional complexity, and longer-term outcomes such as longevity, reproductive performance and incidence of disease are not well characterised. Protracted exposure to many types of stressor is recognized to generate negative affective states and to be associated with increased mortality and poor health outcomes in humans and animals (Mason et al. 2012). Thus, affective states may provide a plausible link between resilience and the outcomes associated with resilience. There is increasing emphasis in studies of animal welfare of the need to not only minimise harms but to also enable the animal to achieve positive welfare outcomes (Yeates and Main 2008; Mellor 2015; Lawrence et al. 2019; Mattiello et al. 2019) (Figure 2). Does resilience merely minimise harms or is resilience an aspect of positive welfare? If resilience provides a measure of positive welfare, does it do so as a proxy for positive affect, or does resilience represent an aspect of positive welfare not captured solely by positive affect?

The nature of positive welfare and methods for its assessment are topics under rapid advancement (reviewed by Yeates and Main 2008; Mellor 2015; Mellor 2016; Lawrence et al. 2019; Mattiello et al. 2019; Rault et al. 2020). Lawrence et al. (2019) suggest that the concept of positive welfare includes 
1) positive affective states, 2) engagement with the environment in a manner that provides positive affective experiences, 3 ) quality of life arising from the balance of positive and negative states, and 4) happiness across the whole of the animal's life. This view aligns positive welfare with opportunities for achieving and experience hedonic wellbeing. Nonetheless, in philosophical and empirical studies, two strands of wellbeing have been recognized, hedonic and eudaimonic (Ryff et al. 2004; Nordenfelt 2006, 2011; Fredrickson 2016; Rault et al. 2020; Williams 2021). Eudaimonia describes the capacity of the animal to express agency, function well, and fulfil biological potential which together enable the animal to display mastery of its environment (Ryff et al. 2004; Fredrickson 2016; Williams 2021). This has been termed "doing" by Lawrence et al. (2019). From a human perspective, the eudaimonic dimension of wellbeing can be captured by the epigram "I function well, therefore I flourish." It differs from the hedonic perspective of wellbeing which for humans can be characterised as "I feel well, therefore I am well." In the style of Lawrence et al. (2019), hedonic wellbeing can be abbreviated to "feeling" (e.g. Robbins et al. 2018; Duncan 2020). A third strand centred on social wellbeing is also described in some frameworks of human and animal wellbeing (Williams 2021) which can be termed "interacting".

Rault et al. (2020) and Williams (2021) emphasize the importance of developing indicators of eudaimonia to advance studies on positive animal welfare. Some preliminary lines of evidence for potential indicators come from studies in humans and rodents. Self-report of indicators of eudaimonic wellbeing in humans are associated with a gene transcription pattern in leukocytes that accompanies strong antibody and antiviral defence (Cole et al. 2015). The transcription pattern is shifted to a proinflammatory profile, termed the conserved transcriptional response to adversity, by early life adversity and by a range of stressors, and is associated with poor health outcomes (Fredrickson et al. 2015). Surprisingly, the (undesirable) pro-inflammatory profile is also positively associated with indicators of hedonic wellbeing (Fredrickson 2016). The same effect of stressors on leukocyte gene transcription is observed in rodents and rhesus monkeys (Cole 2019). In accord with these findings, in independent studies in humans, eudaimonic wellbeing was associated with lower concentrations of daily salivary cortisol, pro-inflammatory cytokines, metabolic markers of cardiovascular risk, and longer duration REM sleep; a pattern not seen for indicators of hedonic wellbeing (Ryff et al. 2004). Contrary results have also been reported (reviewed by Williams 2021). Despite divergence in biomarkers between eudaimonic and hedonic wellbeing, these two (or three) aspects of wellbeing are closely intertwined in humans and the authors interpret their findings as pointing to benefits associated with indicators of eudaimonia rather than harms accompanying indicators of hedonia (Fredrickson 2016).

Another line of evidence supporting the role of normalcy of biological functioning in generating positive wellbeing is provided by the hypothalamic pituitary adrenal (HPA) axis. In all mammals examined, including sheep (Fulkerson 1978), cortisol production exhibits circadian and ultradian patterns that are influenced by genetic background, sex hormones, neonatal epigenetic programming, environmental stressors and age (Russell et al. 2015). The circadian pattern of HPA activity modulates mood and metabolic, immunoregulatory, and cognitive activities in anticipation of the activity cycles of the animal (Russell et al. 2015; Kalafatakis et al. 2021). Disruption of the circadian and ultradian patterns increases susceptibility to a variety of physical and psychological stressors, and animals (rats and humans) with more pronounced circadian and ultradian patterns 
exhibit greater resilience to stressors (Spiga and Lightman 2020). Thus, circadian and ultradian rhythms increase resilience during the period of heighten risk of exposure to stressors that accompanies activity. These studies on periodicity of HPA axis function lend support to findings on measures of periodicity of other physiological and behavioural variables as indicators of resilience and eudaimonic wellbeing (Scheibe et al. 1999; Nunes Marsiglio Sarout et al. 2018; Van Dixhoorn et al. 2018; Sun et al. 2021).

This background supports the proposition that uniformity of performance trajectories and periodicity of physiological cycles provide signs of mastery by the individual of its personal environment. These measures of resilience may indicate not only that the animal is coping with the potential harms posed by its environment but is also expressing a positive state of eudaimonic wellbeing that enables it to thrive. It is important to note that these measures are indicators of systemic or whole-of-animal resilience (Scheffer et al. 2018). The analytical methods assess the "structure" within biological functions rather than the mechanistic interactions between components that underlie particular functions. Thus, where resilience is indicated as low, the measures may lack specificity for identifying the welfare domain (nutrition, environment, health, behaviour, or affective mental state (Mellor and Beausoleil 2015)) or welfare criterion (Veissier et al. 2009) in which provisions or biological functions are deficient (Figure 3). Thus, dynamic indicators of resilience, and the eudaimonic state inferred from the indicators, represent a higher-order level of welfare assessment than domain-specific indicators of hedonic positive welfare currently under development for example as described for ruminants by Mattiello et al. (2019).

\section{Competence}

A framework for interpreting the beneficial effects of biological functions in support of eudaimonic wellbeing is provided by the concept of competence. Waddington (1957) developed the idea of competence to describe the acquisition of responsiveness to developmental cues by cells and organs during ontogeny. The concept of competence is widely used in biology and has been extended from Waddington's limited application in embryogenesis to describe emergence of biological functions on both phylogenetic and ontogenetic time scales. It is the development of functions such as immunity, social skills and coping skills during the lifespan of the individual that is of importance in the current context. Such functionalities often exhibit phases of rapid maturation during periods of heightened sensitivity to the inductive effects of environmental stimuli, although acquisition of competence can continue outside sensitive periods and continue into adult life (Mellor 2019; Colditz 2020; Lyons and Schatzberg 2020). Following its early historical description in sense organs (Hubel and Wiesel 1970) the concept of competence has been extended to describe development of functionalities in reproduction, immunity (Miller 1963), physiology (Timiras 1996) and psychology (White 1959; Hintze and Yee 2021; Williams 2021). For example, play can be understood to contribute to the development of competence in long-term social, muscle motor and kinaesthetic (proprioceptive) capabilities that contribute to agency as well as providing short-term hedonic rewards (Spinka et al. 2001; Spinka and Wemelsfelder 2011). Competence also underpins the notion of hormesis (LópezOtín and Kroemer 2021), that is, the induction of tolerance to stressors by low-dose exposure in an appropriate context during developmental stages (Lyons and Schatzberg 2020). Acquired tolerance or "learning to cope" has been studied as a competence in humans, monkeys and mice that can be 
acquired through exposure to conducive experiences (Lyons and Schatzberg 2020). Although competencies are developmentally acquired through experience, genetic variation exists in the capacity of the animal to develop competencies, as seen for example in the heritable variation in immune competence in beef cattle (Reverter et al. 2021). A critical feature of the acquisition of competencies is the role of appropriate environmental conditions. This role of engagement with enriching environments in development and ongoing realisation of competencies underpins the "provision" statements in the Five Freedoms and the Five Domains frameworks (Mellor 2015; Mellor 2016). Thus, the role of competencies in realising physiological, cognitive and affective potential of the animal anchors them firmly within the concept of positive welfare.

\section{Positive health}

Studies on indicators of eudaimonia in humans and other animals have led to the development of the concept of positive health (Ryff et al. 2004; López-Otín and Kroemer 2021). In this view, "health is an active process that enables an organism to adapt to fluctuations in its intrinsic and extrinsic environments to maintain health or recover to a healthy state after disease occurs" (Ayres 2020). This view recognizes a distinction between defence mechanisms such as those centred on immune functions that antagonize infections, and pro-active physiological, behavioural and psychological mechanisms that promote health (Ayres 2020; Medzhitov 2021) (Figure 4). Thus, positive health is more than the absence of ill-health. Defence mechanisms are typically associated with a catabolic state whereas the pro-active mechanisms supporting positive health are associated with an anabolic state (Ye and Medzhitov 2019). The concept of health as a continuum was highly influential in the development of the concept of animal welfare as a continuum from poor to good (Broom 1996). Yet the concept of health, like other abstract concepts discussed in this review attracts diverse opinions as to its character and the indicators that signal its occurrence (Lerner 2020). This ambiguity is illustrated by a review of the use of the concept in 500 textbooks of veterinary medicine and pathology. Gunnarsson (2006) suggests the definitions of veterinary health used in these textbooks fall into five categories: 1) normality; 2) biological function; 3) homeostasis; 4) physical and psychological well-being; and 5) productivity including reproduction. It is noteworthy that $92 \%$ of the surveyed texts relied on the reader's intuitive understanding of the concepts of health and disease. Studies on resilience and regulation of host defence (e.g. Lyons and Schatzberg 2020; López-Otín and Kroemer 2021; Medzhitov 2021) illustrate the opportunity for further development of resilience measures as indicators of positive health, and positive health as an aspect of positive welfare. The mechanistic differences between host defence and positive health identified by Ayres (2020), Lyons and Schatzberg (2020), López-Otín and Kroemer (2021) and (Medzhitov 2021) support a distinction between elimination and control of harms through "competence to cope" and prediction and avoidance of harms in support of flourishing of the animal through "competence to thrive" (Figure 4).

\section{A continuum of affective experience}

Central to the conventional concept of positive welfare as described above is positive hedonic affective experience. A framework that links eudaimonia and hedonia as aspects of positive welfare is provided by considering the continuum of affective experience. Animals are thought to 
continuously exist in an affective state described as a psychological space with dimensions of hedonic valence and arousal (Russell 2003; Mendl et al. 2010; Kremer et al. 2020) (Figure 5). Valence describes attractiveness or aversiveness and arousal describes the level of psychological activation of affective experience. Both valence and arousal influence autonomic nervous system functions and are hence associated with changes in physiological arousal (Satpute et al. 2019). In humans, selfreport provides the foundation for assessment of affective states, however as self-report is not available for non-human animals (or prelingual infants), physiological and behavioural changes can provide proxies for affective states (Russell 2003; von Borell et al. 2007; Hemsworth et al. 2015). Transient affective states that change over short time frames (moments to minutes) are described as emotions which typically have an object focus on events in the internal and external environments of the animal (Russell 2003; Mendl et al. 2010; Kremer et al. 2020). In contrast to emotions, affective experiences that dwell over periods from hours to days generate free-floating moods that are less focussed on events and that more closely align with an accumulation of recent affective experience (Russell 2003; Mendl et al. 2010; Kremer et al. 2020). Like emotions, moods are described as representing the position of the animal in psychological affective space with dimensions of valence and energy (arousal) (Russell 2003; Mendl et al. 2010; Kremer et al. 2020) (Figure 5). The physiological manifestation of the energy of moods is captured in descriptors such as dull, depressed, active, and energised and the valenced dimension by behaviours such as sickness behaviour (negatively valenced) (Johnson 2002) and play (positively valenced) (Špinka 2012). It is evident that sickness behaviour is accompanied by a low energy state and play by a high energy state. The co-expression of energy and valence in the psychological state associated with play and sickness behaviour illustrate the important point that the position of the animal in affective space cannot be described solely by proxy measures of either arousal (energy) or valence (Russell 2003; Mendl et al. 2010; Kremer et al. 2020). It is suggested here that the two dimensions of affective experience may dwell over the longer time frames of seasons, years and the whole life of the animal to manifest as eudaimonic and hedonic wellbeing (Figure 5). The persistence of eudaimonic and hedonic states over long intervals of time is well recognized in humans (e.g. Ryff et al. 2021). In this model, neither eudaimonia nor hedonia can alone provide a complete description of the psychological affective experience of wellbeing. The model is consistent with the proposition that an animal can experience simultaneously divergent levels of eudaimonic and hedonic wellbeing (Williams 2021). For example, an aged cow may have poor eudaimonic wellbeing from the privations of advancing age while experiencing good hedonic wellbeing associated with suckling, grooming, and being groomed by her calf. This reiterates the observation that good health and positively valenced affective experience can occur independently and are not synonymous (Duncan and Dawkins 1983).

The physical aspects of eudaimonic function that have been captured to date by measures of resilience have largely focussed on variability of performance in the time frame of days to seasons. Whole-of-life measures to extend this time frame may be provided by cumulative measures of health, longevity, evolutionary fitness, and the success of the animal in achieving its inherited and developmentally acquired capacity for performance (Figure 5). Measures of the hedonic valence of affective experience that dwell over time frames from days to whole-of-life would complement eudaimonic measures in describing the whole-of-life welfare of the animal. Cumulative scores of affect balance and affective hedonic happiness have been proposed as measures to assesses such 
long-term hedonic wellbeing in animals (Mellor 2016; Webb et al. 2018; Kremer et al. 2020; Keeling et al. 2021).

In the transition from transient emotions to longer-lasting moods the character of affect is thought to change from an object focus to a diffuse experience (Russell 2003; Mendl et al. 2010).

Accompanying this shift in focus is a transition from acute alterations in autonomic nervous system functions that manifest as arousal to longer lasting changes in kinetic energy that manifest as strength of motivations and behavioural activity levels (Mendl et al. 2010; Kremer et al. 2020). These transitions in system functions between emotions and mood highlight an important question whether there are further transitions in system functions that only become manifest in the psychological states of long term eudaimonic and hedonic wellbeing. In this scenario, wellbeing (and welfare) would be more than the sum of biological functions and valenced experience measured on ultradian, circadian and daily time scales, and would require measures of whole-of-animal properties that are not expressed on the time scales of moments and days. In the Domains Model of welfare assessment, the mental state arising from positive or negative affective engagement is proposed to provide an integrated sum of internal states and external circumstances (Mellor and Beausoleil 2015). To date, indicators of positive affective experience under development for assessment of positive welfare have largely focused on behaviours that are indicative of positively valenced states (Lawrence et al. 2019; Mattiello et al. 2019; Keeling et al. 2021). It is suggested here that when affective experienced is parsed into eudaimonic and hedonic dimensions that resilience indicators can be understood to provide integrated measures of eudaimonic healthy physical functioning that extend the suite of indicators available for the assessment of positive welfare. This can help satisfy the recognized need for tools to assess eudaimonic wellbeing (Lawrence et al. 2019; Rault et al. 2020; Williams 2021).

\section{Conclusions}

The capacity of an animal to exhibit minimal disturbance to its normal patterns of physiological, behavioural and performance activities in the face of variations in its micro-environment provide signs of its competence to thrive and to fulfil its inherited and developmentally acquired potential. Animals express consistent individual differences from their conspecifics in performance trajectories (e.g. growth rate), biorhythms (e.g. chronotypes (Refinetti et al. 2016)) and complexity of social interactions (e.g. dominance). Longitudinal data enable estimation of deviation from the pattern that is normal for the individual, whereas cross-sectional data necessitates estimation of deviation from the pattern that is normal for the population. The micro-environment, which is also termed the "non-shared environment" in co-housed animals (Freund et al. 2013), describes the individual perspective an animal has of its conditions. In this respect, measures of resilience address the need in animal welfare science to assess the conditions the individual animal experiences from its own perspective (Dawkins 2006). Differences between individuals in the occurrence of deviations across time while they are being managed within a shared macro-environment confirm that resilience can measure the individual animal's experience of its non-shared micro-environment, and that differences between individuals can occur in the absence of any overt macro-environmental disturbance (Nunes Marsiglio Sarout et al. 2018; Garcia-Baccino et al. 2021). Resilience assessed by these parameters of individual normalcy may provide new indicators of health, biological functioning 
and the state of the individual animal as it attempts to cope with its environment. The continuous monitor of animals and their environment by sensor technologies has come to be termed precision livestock farming (Schillings et al. 2021). The analytic strategies being developed to assess resilience when combined with genomic predictions of individual animal performance should enable the development of a "personalised medicine" approach to precision welfare assessment.

Although the conceptual construct of resilience may be hidden from direct measurement, pragmatic measures based on physiological, behavioural and performance variables expressed in the routine production environment and during periods of husbandry-induce stress such as weaning, change of diet or social regrouping may inform refinement of the conceptual construct. This pragmatic approach aligns with Dawkins' suggestion that it is not necessary to unravel the role of consciousness in affect and emotion in order to establish the valence of animal experience through behavioural assessment of "what animals want" (Dawkins 2021). Biological costs to the animal of resilience may be less than the costs of adaptation (Strandberg 2009; Ayres 2020; Garland Jr et al. 2022) and deserve further research.

It is well recognised that harms and deprivations are sufficient to reduce welfare of an animal in any prior degree of good welfare (Broom 1986) (Figure 2), and that to sustain good welfare requires not only the minimisation of harms but also the cumulative combination of what can be termed "competencies to thrive" based on healthy functioning across behavioural, immunological, physiological, cognitive and affective domains (Mellor 2016). An important question for development of indicators of positive welfare is whether these competencies represent a eudaimonic dimension of positive welfare or only indirectly contribute to positive welfare through the provision of opportunities for positive hedonic affective experience (Hemsworth et al. 2015; Mellor 2016; Weary and Robbins 2019). Both modes of influence seem likely, as suggested both by theory (Williams 2021), by empirical studies on folk intuitions of good welfare (Robbins et al. 2018) and as summarised in Figure 5. Thus, it is suggested that health and proper biological functioning, which have long been recognised as important aspects of welfare, not only indicate the absence of harms but can also indicate a eudaimonic state of positive welfare. Resilience may provide a sensitive indicator of eudaimonia. In this view, positive welfare entails both eudaimonic and hedonic aspects of wellbeing, neither of which is alone sufficient to describe the state of positive welfare, nor alone sufficient to maximise positive welfare.

The utility of measures of trajectories, biorhythms, and functional complexity as indictors of the current state of the animal, as predictors of future outcomes or as phenotypes for genetic evaluation does not depend on the validity of the constructs of resilience, competence, positive health or eudaimonia presented in this review. Rather their utility lies within empirical relationships established through field studies. Further refinement of the constructs and their relationship with animal measures should help improve assessment of animal welfare and our understanding of the biology of "doing". It is noteworthy that numerous studies in humans report a circadian periodicity in positive mood that is disrupted in states of physical and psychological dysfunction (Kalafatakis et al. 2021 and references therein). It is highly likely similar periodicity occurs in animals. If biosensors for detecting physiological and behavioural proxies of positively-valenced mood can be developed for animals, then the parameters of normativity used to assess resilience may provide simple 
measures of hedonic wellbeing that can help advance understanding of the biology of "feeling" in farm animals.

The opportunity to breed animals for resilience does not diminish the importance of minimizing the risk of harms by good management of animals of appropriate genetic background in well-designed environments. Cumulative scores of resilience may provide a method for quantifying one aspect of the whole-of-life welfare of the individual (Nunes Marsiglio Sarout et al. 2018; Poppe et al. 2021a; Friggens et al. 2022), as well as provide a tool for benchmarking welfare performance between farms. Further work on development of these measures of resilience and their application to welfare assessment is warranted. These new measures enabled by sensor-derived longitudinal data offer the opportunity to detect the impact of "periods of acute, but transitory, physical or mental suffering" on the animal that Brambell and colleagues (1965) recognized provide a limitation to use of "growth and condition" as indicators of welfare.

\section{Data availability statement}

Data sharing is not applicable as no new data were generated or analysed during this study.

\section{Conflicts of interest}

The author declares no conflicts of interest.

\section{Acknowledgements}

Comments on a draft of the paper by Caroline Lee and Aaron Ingham are gratefully acknowledged. 
Figure 1

(a)

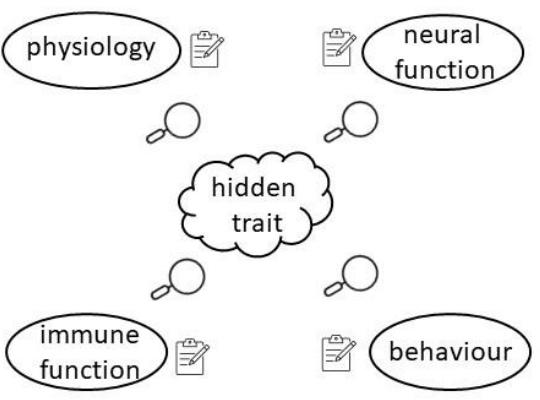

(c)

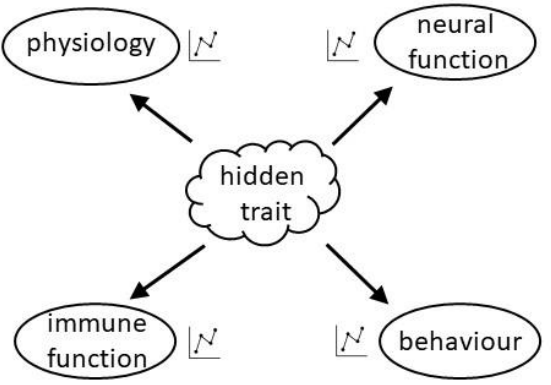

(b) physiology $N \quad N \quad \begin{aligned} & \text { neural } \\ & \text { function }\end{aligned}$

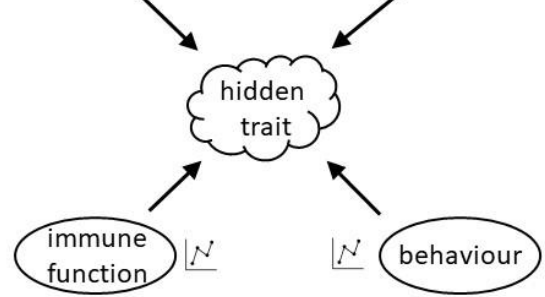

(d)

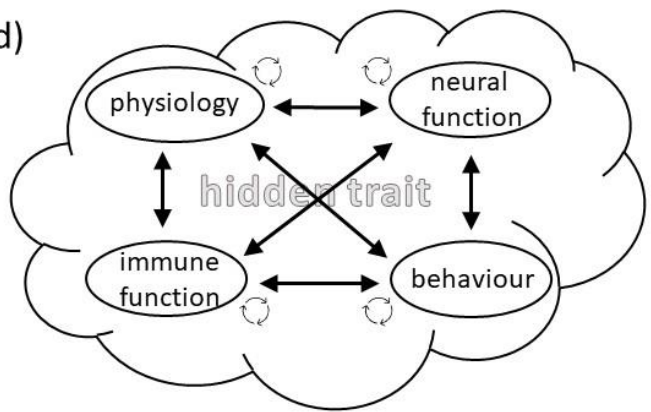


Figure 2

Harms

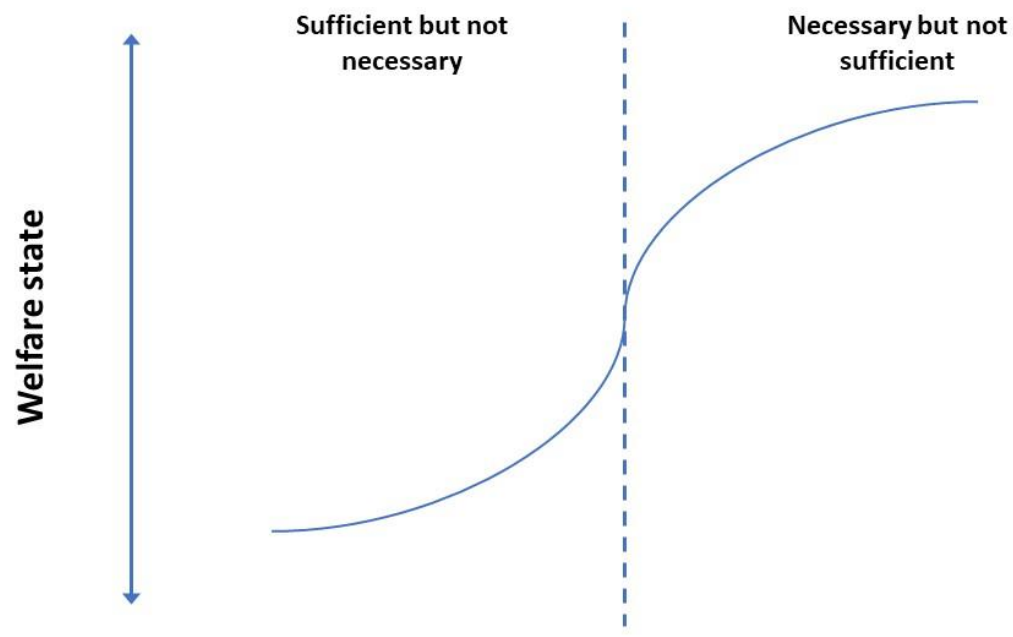

Association with welfare 
Figure 3

\section{Measures of resilience}

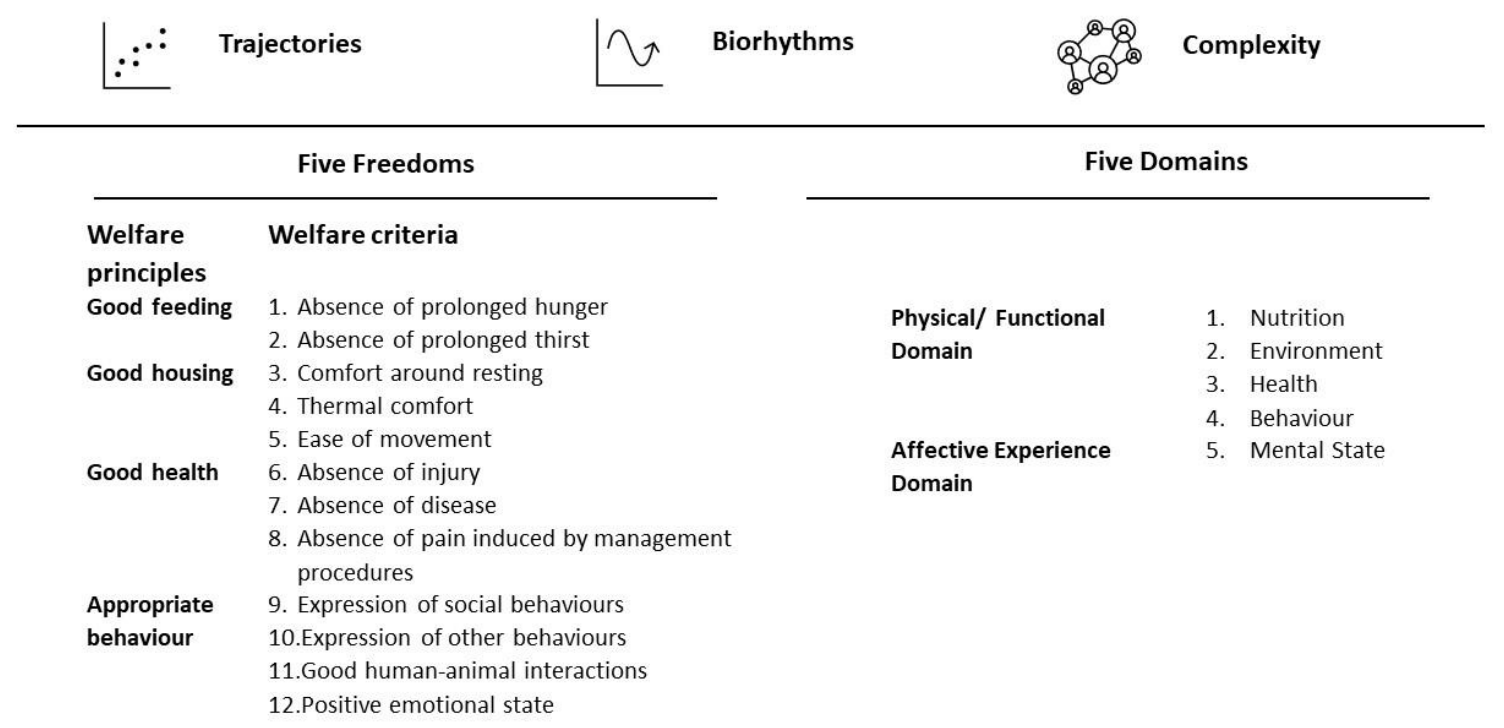


Figure 4

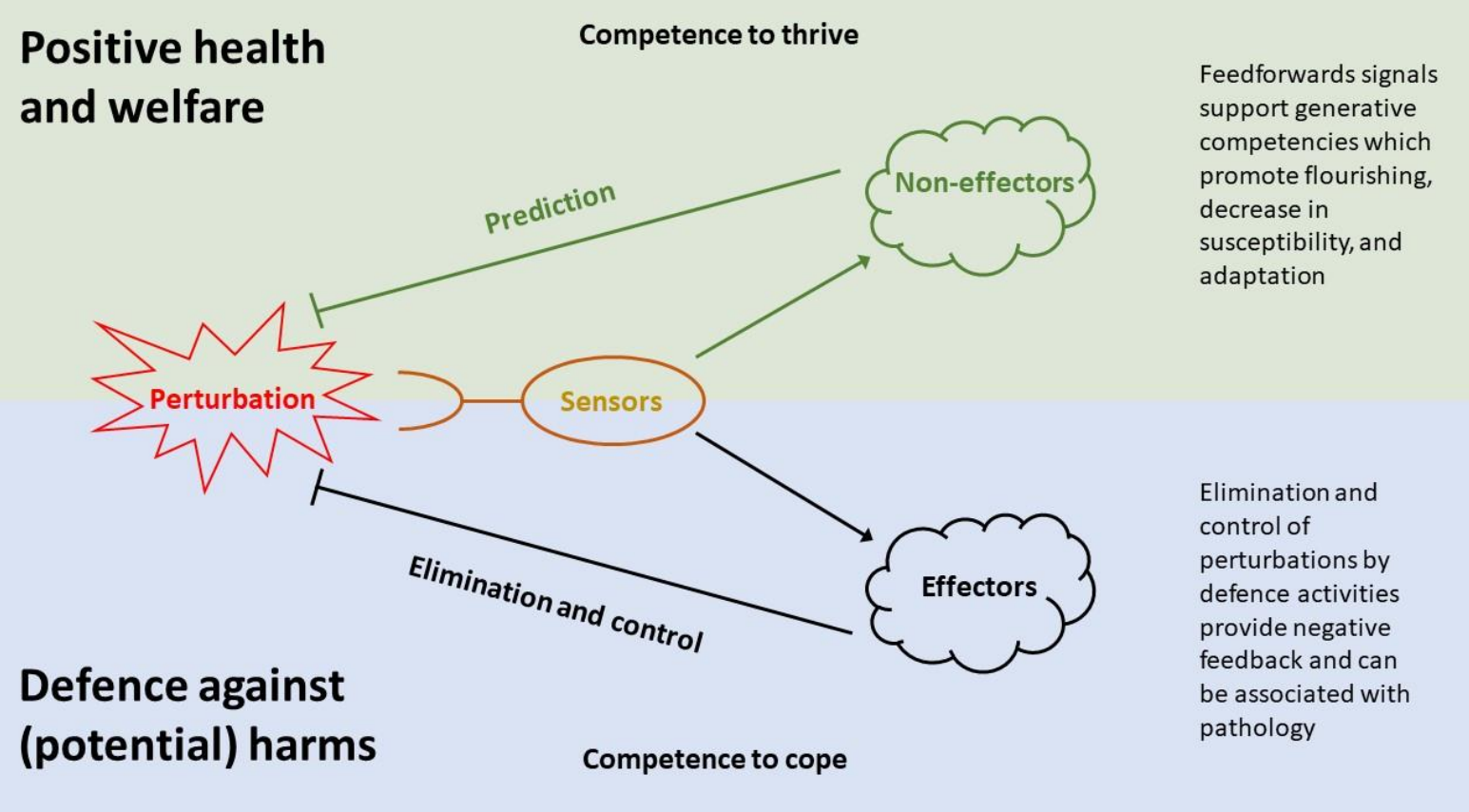


Figure 5

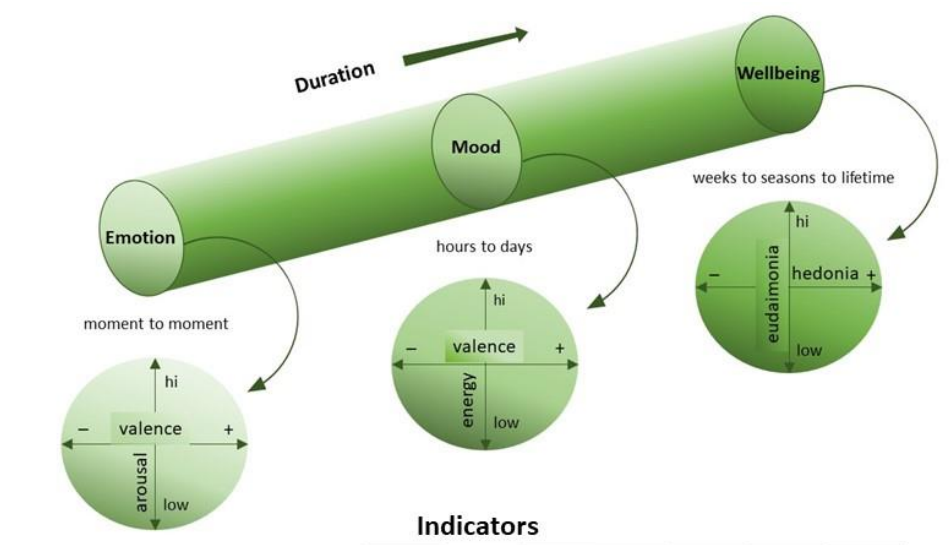

\begin{tabular}{|c|c|c|c|c|c|}
\hline \multicolumn{2}{|c|}{ Emotion } & \multicolumn{2}{|c|}{ Mood } & \multicolumn{2}{|c|}{ Wellbeing } \\
\hline arousal & valence & energy & valence & eudaimonia & hedonia \\
\hline \multirow[t]{2}{*}{$\begin{array}{l}\text { - heart rate } \\
\text { variability } \\
\text { - eve temperature } \\
\text { - skin temperature } \\
\text { - stress-induce } \\
\text { hyperthermia } \\
\text { - autonomic tone }\end{array}$} & $\begin{array}{l}\text { - startle } \\
\text { - attention bias } \\
\text { - ear posture } \\
\text { - facialexpressions } \\
\text { - vocalisations }\end{array}$ & $\begin{array}{l}\text { Descriptors } \\
\text { - depressed } \\
\text { - enervated } \\
\text { - dull } \\
\text { - energized }\end{array}$ & \begin{tabular}{|l} 
- cognitive bias \\
- preference \\
- motivation \\
- qualitative \\
behavioural \\
assessment \\
\end{tabular} & \multirow{2}{*}{$\begin{array}{l}\text { - cumulative } \\
\text { measures of variation } \\
\text { in ultradian, circadian } \\
\text { and daily patterns } \\
\text { - seasonal and } \\
\text { lifetime measures of } \\
\text { function and fitness } \\
\text { - realisation of } \\
\text { inherited and } \\
\text { developmentally- } \\
\text { acquired potentials }\end{array}$} & \multirow{2}{*}{$\begin{array}{l}\text { cumulative valenced } \\
\text { measures of mood, } \\
\text { happiness, balance of } \\
\text { positive versus } \\
\text { negative affect, } \\
\text { qualitative } \\
\text { behavioural } \\
\text { assessment, etc }\end{array}$} \\
\hline & & $\begin{array}{l}\text { metabolic rate), } \\
\text { patterns, play, in } \\
\text { roduction (e.g. }\end{array}$ & $\begin{array}{l}\text { circadian and daily } \\
\text { (le.g. temperature, } \\
\text { viour (e.g. activity } \\
\text {,valence and } \\
\text { vield, body weight) }\end{array}$ & & \\
\hline
\end{tabular}




\section{Figure captions.}

Figure 1 The relationships between measurements or scores made of an animal and a hidden trait or conceptual construct such as fear, temperament or resilience can take a number of forms, four of which are shown here. (a) scores made on the animal reveal aspects of the hidden construct but are not causally linked to the construct. (b) (c) (d) causal links lie between the hidden construct and biological functions that can be assessed by measurement of variables in those functions. (b) biological functions such physiological, behavioural, immune and neural activities are causes of the hidden trait. (c) the hidden trait causes changes in biological functions such as physiological, behavioural, immune and neural activities. (d) the hidden trait is embedded within a network of biological functions such as physiological, behavioural, immune and neural activities and is an emergent property of the activities within the network. More complex nested hierarchies of causation occur than are represent here.

Figure 2 The welfare state of an animal falls on a continuum from poor to positive. The point of inflection between positive and poor welfare does not occur at a fixed sum of harms versus competences. Rather it can occur at any point where the influence of any single factor becomes sufficient for it to constitute a harm and reduce welfare, although any specific individual harm is not necessary for a state of poor welfare to exist. Positive welfare depends on the occurrence of multiple "competencies to thrive" that are each necessary but are not individually sufficient for positive welfare to occur. Characterisation and assessment of competencies to thrive as indicators of eudaimonic and hedonic wellbeing requires further research.

Figure 3 Measures of resilience based on trajectories, biorhythms and complexity can provide integrated indicators of the eudaimonic dimension of positive affective experience. The measures, however, can lack specificity to identify in which welfare criterion of the Five Freedoms model (Veissier et al. 2009) or welfare domain of the Five Domains model (Mellor and Beausoleil 2015) deficiencies in biological functioning occur when resilience is low. In the tripartite model of animal wellbeing (Williams 2021), complexity of social interactions (Asher et al. 2009) might provide an indicator of social wellbeing.

Figure 4 Perturbations in the structure, function or regulation of tissues, processes and activities of the animal are detected by sensors which stimulate effector defence processes that provide negative feedback on the causes of the perturbation by its elimination or control and underpin "competence to cope". Signals from sensors provide feedforward stimuli to non-effector tissues promoting generative competencies that support thriving, loss of susceptibility, and adaptation to the causes of perturbation. Together these 
feedforward signals promote "competence to thrive" that generates a eudaimonic state of positive health and positive welfare.

Figure 5 The animal occupies an affective space with dimensions of hedonic valence and psychological arousal. Position in affective space can vary over time frames that change from moment to moment (emotions) or hours to days (moods). It is suggested here that wellbeing represents a persistence of affective experience over periods that last from weeks to seasons to whole of life. The eudaimonic and hedonic dimensions of wellbeing may be aspects of affective valence and arousal. As animals are unable to self-report their affective experiences, valence and arousal of emotions and moods can be assessed through physiological, behavioural and cognitive proxies. Most measures of resilience that have been developed to date examine physiological functions associated with the time frame of moods. Eudaimonia may represent the accumulation of short-term physiological functions as well as functions of the animal such as longevity and fitness that only manifest over longer time frames. Resilience measures developed to date address the eudaimonic dimension but are largely lacking for the hedonic dimension of wellbeing. Resilience measures of hedonic wellbeing are plausible, such as periodicity of positively-valenced mood. 


\section{References}

Abdelkrim, AB, Puillet, L, Gomes, P, Martin, O (2021) Lactation curve model with explicit representation of perturbations as a phenotyping tool for dairy livestock precision farming. Animal 15, 100074.

Adriaens, I, Friggens, N, Ouweltjes, W, Scott, H, Aernouts, B, Statham, J (2020) Productive life span and resilience rank can be predicted from on-farm firstparity sensor time series but not using a common equation across farms. Journal of Dairy Science 103, 7155-7171.

Albers, GAA, Gray, GD, Piper, LR, Barker, JSF, Le Jambre, LF, Barger, IA (1987) The genetics of resistance and resilience to Haemonchus contortus in young Merino sheep. International Journal for Parasitology 17, 1355-1363.

Aleri, JW, Hine, BC, Pyman, MF, Mansell, PD, Wales, WJ, Mallard, B, Stevenson, MA, Fisher, AD (2019) Associations between immune competence, stress responsiveness, and production in Holstein-Friesian and Holstein-FriesianJersey heifers reared in a pasture-based production system in Australia. Journal of Dairy Science 102, 3282-3294.

Asher, L, Collins, LM, Ortiz-Pelaez, A, Drewe, JA, Nicol, CJ, Pfeiffer, DU (2009) Recent advances in the analysis of behavioural organization and interpretation as indicators of animal welfare. Journal of the Royal Society Interface 6, 1103-1119.

Ayres, JS (2020) The biology of physiological health. Cell 181, 250-269.

Baffy, G, Loscalzo, J (2014) Complexity and network dynamics in physiological adaptation: An integrated view. Physiology \& Behavior 131, 49-56.

Bai, X, Plastow, GS (2022) Breeding for disease resilience: opportunities to manage polymicrobial challenge and improve commercial performance in the pig industry. CABI Agriculture and Bioscience 3, 6.

Bauman, DE (2000) Regulation of nutrient partitioning during lactation: homeostasis and homeorhesis revisited. In 'Ruminant physiology: digestion, metabolism, growth and reproduction.' (Ed. PB Cronj,.) pp. 311-328. (CAB International: Wallingford)

Bauman, DE, Currie, WB (1980) Partitioning of nutrients during pregnancy and lactation: a review of mechanisms involving homeostasis and homeorhesis. Journal of Dairy Science 63 1514-1529.

Bell, AW, Bauman, DE (1997) Adaptations of glucose metabolism during pregnancy and lactation. Journal of mammary gland biology and neoplasia 2, 265-278.

Berghof, T, Bovenhuis, H, Mulder, H (2019) Body weight deviations as indicator for resilience in layer chickens. Frontiers in genetics 10, 1216.

Berghof, T, Poppe, M, Mulder, H (2018) Opportunities to improve resilience in animal breeding programs. Frontiers in genetics 9, 692.

Bishop, SC (2012) A consideration of resistance and tolerance for ruminant nematode infections. Frontiers in genetics 3: Article 168,

Bisset, SA, Morris, CA (1996) Feasibility and implications of breeding sheep for resilience to nematode challenge. International Journal for Parasitology 26, 857868.

Botreau, R, Veissier, I, Butterworth, A, Bracke, MB, Keeling, LJ (2007) Definition of criteria for overall assessment of animal welfare. Animal Welfare 16, 225-228. 
Brambell, FWR (1965) Report of the technical committee to enquire into the welfare of animals kept under intensive livestock husbandry systems The Brambell Report, December 1965. London: Her Majesty's Stationary Office. ISBN 0108502864. $H M$

Brito, L, Rojas De Oliveira, H, McConn, B, Schinckel, A, Arrazola, A, Marchant-Forde, JN, Johnson, J (2020) Large-scale Phenotyping of Livestock Welfare in Commercial Production Systems: A New Frontier in Animal Breeding. Frontiers in genetics 11, 793.

Broom, DM (1986) Indicators of poor welfare. British Veterinary Journal 142, 524-526.

Broom, DM (1996) Welfare defined in terms of attempts to cope with the environment. Acta Agric. Scand. Sec. A. Anim. Sci. Suppl 27, 22-28.

Bruineberg, J, Kiverstein, J, Rietveld, E (2018) The anticipating brain is not a scientist: the free-energy principle from an ecological-enactive perspective. Synthese 195, 2417-2444.

Burrow, HM (1997) Measurements of temperament and their relationship with performance traits of beef cattle. Animal Breeding Abstracts 65, 477-495.

Bushby, EV, Friel, M, Goold, C, Gray, H, Smith, L, Collins, LM (2018) Factors influencing individual variation in farm animal cognition and how to account for these statistically. Frontiers in veterinary science 5, 193.

Careau, V, Garland Jr, T (2012) Performance, personality, and energetics: correlation, causation, and mechanism. Physiological and Biochemical Zoology 85, 543-571.

Carter, AJ, Feeney, WE, Marshall, HH, Cowlishaw, G, Heinsohn, R (2013) Animal personality: what are behavioural ecologists measuring? Biological reviews $\mathbf{8 8}$, 465-475.

Cartwright, S, Schmied, J, Livernois, A, Mallard, B (2022) Effect of In-vivo Heat Challenge on Physiological Parameters and Function of Peripheral Blood Mononuclear Cells in Immune Phenotyped Dairy Cattle. arXiv preprint arXiv:2201.02675

Cartwright, SL, McKechnie, M, Schmied, J, Livernois, AM, Mallard, BA (2021) Effect of invitro heat stress challenge on the function of blood mononuclear cells from dairy cattle ranked as high, average and low immune responders. Bmc Veterinary Research 17, 233.

Clunies Ross, I (1932) Observations on the resistance of sheep to infestation by the stomach worm (Haemonchus contortus). Journal of the Council for Scientific and Industrial Research 5, 73-80.

Colditz, IG (2018) Objecthood, Agency and Mutualism in Valenced Farm Animal Environments. Animals 8, 50.

Colditz, IG (2020) A consideration of physiological regulation from the perspective of Bayesian enactivism. Physiology \& Behavior 214, 112758.

Colditz, IG (2021) Adrenergic tone as an intermediary in the temperament syndrome associated with flight speed in beef cattle. Frontiers in Animal Science 2, 6.

Colditz, IG, Ferguson, DM, Collins, T, Matthews, L, Hemsworth, PH (2014) A prototype tool to enable farmers to measure and improve the welfare performance of the farm animal enterprise: The Unified Field Index. Animals 4, 446-462.

Colditz, IG, Hine, BC (2016) Resilience in farm animals: biology, management, breeding and implications for animal welfare. Animal Production Science 56, 1961-1983.

Cole, SW (2019) The conserved transcriptional response to adversity. Current Opinion in Behavioral Sciences 28, 31-37. 
Cole, SW, Levine, ME, Arevalo, JMG, Ma, J, Weir, DR, Crimmins, EM (2015) Loneliness, eudaimonia, and the human conserved transcriptional response to adversity. Psychoneuroendocrinology 62, 11-17.

Dawkins, MS (2006) Through animal eyes: What behaviour tells us. Applied Animal Behaviour Science 100, 4-10.

Dawkins, MS (2021) 'The Science of Animal Welfare: Understanding What Animals Want.' (Oxford University Press, USA:

Doeschl-Wilson, A, Knap, P, Opriessnig, T, More, S (2021) Livestock disease resilience: from individual to herd level. Animal 15, 100286.

Duncan, IJH (2020) The Philosophical and Biological Evolution of Feelings in Well-being. In 'Mental Health and Well-being in Animals.' (Ed. FD McMillan.) pp. 21. Wallingford)

Duncan, IJH, Dawkins, MS (1983) The problem of assessing "well-being" and "suffering" in farm animals. In 'Indicators Relevant to Farm Animal Welfare.' (Ed. D Smidt.) Vol. 23 pp. 13-24. Dortrecht)

Eady, SJ, Woolaston, RR, Barger, IA (2003) Comparison of genetic and nongenetic strategies for control of gastrointestinal nematodes of sheep. Livestock Production Science 81, 11-23.

Elgersma, GG, De Jong, G, Van der Linde, R, Mulder, HA (2018) Fluctuations in milk yield are heritable and can be used as a resilience indicator to breed healthy cows. Journal of Dairy Science 101, 1240-1250.

Fayers, PM, Hand, DJ (2002) Causal variables, indicator variables and measurement scales: an example from quality of life. Journal of the Royal Statistical Society: Series A (Statistics in Society) 165, 233-253.

Finkemeier, MA, Langbein, J, Puppe, B (2018) Personality research in mammalian farm animals: Concepts, measures, and relationship to welfare. Frontiers in veterinary science $\mathbf{5}$,

Fraser, D (2008) Understanding animal welfare. Acta Veterinaria Scandinavica 50, S1.

Fraser, D, Weary, DM, Pajor, EA, Milligan, BN (1997) A scientific conception of animal welfare that reflects ethical concerns. Animal Welfare 6, 187-205.

Fredrickson, BL (2016) The eudaimonics of positive emotions. In 'Handbook of eudaimonic well-being.' pp. 183-190. (Springer:

Fredrickson, BL, Grewen, KM, Algoe, SB, Firestine, AM, Arevalo, JMG, Ma, J, Cole, SW (2015) Psychological well-being and the human conserved transcriptional response to adversity. Plos One 10, e0121839.

Freund, J, Brandmaier, AM, Lewejohann, L, Kirste, I, Kritzler, M, Krüger, A, Sachser, N, Lindenberger, U, Kempermann, G (2013) Emergence of individuality in genetically identical mice. Science 340, 756-759.

Friggens, N, Adriaens, I, Boré, R, Cozzi, G, Jurquet, J, Kamphuis, C, Leiber, F, Lora, I, Sakowski, T, Statham, J, De Haas, Y (2022) Resilience: reference measures based on longer-term consequences are needed to unlock the potential of precision livestock farming technologies for quantifying this trait. version 4. peer reviewed by Peer Community in Animal Science

https://doi.org/10.5281/zenodo.5729689.

Friggens, NC, Blanc, F, Berry, DP, Puillet, L (2017) Review: Deciphering animal robustness. A synthesis to facilitate its use in livestock breeding and management. Animal 11, 2237-2251. 
Fulkerson, W (1978) Synchronous episodic release of cortisol in the sheep. Journal of Endocrinology 79, 131-132.

Garcia-Baccino, CA, Marie-Etancelin, C, Tortereau, F, Marcon, D, Weisbecker, J-L, Legarra, A (2021) Detection of unrecorded environmental challenges in highfrequency recorded traits, and genetic determinism of resilience to challenge, with an application on feed intake in lambs. Genetics Selection Evolution 53, 1-14.

Garland Jr, T, Downs, CJ, Ives, AR (2022) Trade-Offs (and Constraints) in Organismal Biology. Physiological and Biochemical Zoology 95, 82-112.

Goldstein, DS, Kopin, IJ (2007) Evolution of concepts of stress. Stress 10, 109-120.

Greenwood, P, Clayton, E, Bell, A (2017) Developmental programming and beef production. Animal Frontiers 7, 38-47.

Gunnarsson, S (2006) The conceptualisation of health and disease in veterinary medicine. Acta Vet Scand 48, 20-25.

Guyon, H, Falissard, B, Kop, J-L (2017) Modeling psychological attributes in psychologyan epistemological discussion: network analysis vs. latent variables. Frontiers in psychology 8, 798.

Harlizius, B, Mathur, P, Knol, EF (2020) Breeding for resilience: new opportunities in a modern pig breeding program. Journal of Animal Science 98, S150-S154.

Harris, BN (2020) Stress hypothesis overload: 131 hypotheses exploring the role of stress in tradeoffs, transitions, and health. General and comparative endocrinology 288, 113355.

Haskell, MJ, Simm, G, Turner, SP (2014) Genetic selection for temperament traits in dairy and beef cattle. Frontiers in genetics $\mathbf{5}$,

Hemsworth, PH, Mellor, DJ, Cronin, GM, Tilbrook, AJ (2015) Scientific assessment of animal welfare. New Zealand Veterinary Journal 63, 24-30.

Hine, BC, Acton, GA, Elks, DJ, Niemeyer, DDO, Bell, AM, Colditz, IG, Ingham, AB, Smith, JL (2022) Targeting improved resilience in Merino sheep - Correlations between immune competence and health and fitness trait. Animal

Hine, BC, Bell, AM, Niemeyer, DDO, Duff, CJ, Butcher, NM, Dominik, S, Ingham, AB, Colditz, IG (2019) Immune competence traits assessed during the stress of weaning are heritable and favourably genetically correlated with temperament traits in Angus cattle. Journal of Animal Science 97, 4053-4065.

Hine, BC, Bell, AM, Niemeyer, DDO, Duff, CJ, Butcher, NM, Dominik, S, Porto-Neto, LR, Li, $\mathrm{Y}$, Reverter, A, Ingham, AB (2021) Associations between immune competence phenotype and feedlot health and productivity in Angus cattle. Journal of Animal Science 99, skab016.

Hine, BC, Mallard, BA, Ingham, AB, Colditz, IG (2015) Immune competence in livestock. In 'Breeding Focus 2014 Improving Resilience.' (Eds S Hermesch, S Dominik.) pp. 49-64. (Animal Genetics and Breeding Unit, University of New England: Armidale)

Hintze, S, Yee, JR (2021) Animals in flow-Towards the scientific study of intrinsic reward in animals.

Hubel, DH, Wiesel, TN (1970) The period of susceptibility to the physiological effects of unilateral eye closure in kittens. The Journal of physiology 206, 419-436.

Hurnik, J, Lehman, H (1988) Ethics and farm animal welfare. Journal of Agricultural Ethics 1, 305-318. 
Iung, LHdS, Carvalheiro, R, Neves, HHdR, Mulder, HA (2019) Genetics and genomics of uniformity and resilience in livestock and aquaculture species: A review. Journal of Animal Breeding and Genetics

Jensen, P, Toates, FM (1997) Stress as a state of motivational systems. Applied Animal Behaviour Science 53, 145-156.

Johnson, RW (2002) The concept of sickness behavior: a brief chronological account of four key discoveries. Veterinary Immunology and Immunopathology 87, 443-450.

Kalafatakis, K, Russell, GM, Ferguson, SG, Grabski, M, Harmer, CJ, Munafò, MR, Marchant, N, Wilson, A, Brooks, JC, Thakrar, J (2021) Glucocorticoid ultradian rhythmicity differentially regulates mood and resting state networks in the human brain: A randomised controlled clinical trial. Psychoneuroendocrinology 124, 105096.

Keeling, LJ, Winckler, C, Hintze, S, Forkman, B (2021) Towards a positive welfare protocol for cattle: A critical review of indicators and suggestion of how we might proceed. Frontiers in Animal Science 70.

Kelly, GA, Kahn, LP, Walkden-Brown, SW (2013) Measurement of phenotypic resilience to gastro-intestinal nematodes in Merino sheep and association with resistance and production variables. Veterinary Parasitology 193, 111-117.

Knap, PW, Doeschl-Wilson, A (2020) Why breed disease-resilient livestock, and how? Genetics Selection Evolution 52, 60.

König, S, May, K (2019) Invited review: Phenotyping strategies and quantitative-genetic background of resistance, tolerance and resilience associated traits in dairy cattle. Animal 13, 897-908.

Koolhaas, JM, Bartolomucci, A, Buwalda, B, De Boer, SF, Fluegge, G, Korte, SM, Meerlo, P, Murison, R, Olivier, B, Palanza, P (2011) Stress revisited: a critical evaluation of the stress concept. Neuroscience \& Biobehavioral Reviews 35, 1291-1301.

Kremer, L, Bus, JD, Webb, LE, Bokkers, EA, Engel, B, van der Werf, JT, Schnabel, SK, van Reenen, CG (2021) Housing and personality effects on judgement and attention biases in dairy cows. Scientific Reports 11, 1-18.

Kremer, L, Holkenborg, SEJK, Reimert, I, Bolhuis, JE, Webb, LE (2020) The nuts and bolts of animal emotion. Neuroscience \& Biobehavioral Reviews 113, 273-286.

Kristiansen, TS, Fernö, A (2020) The Predictive Brain: Perception Turned Upside Down. In 'The Welfare of Fish.' (Eds TS Kristiansen, A Fern", MA Pavlidis, H van de Vis.) pp. 211-227. (Springer: Cham)

Lange, J, Dalege, J, Borsboom, D, van Kleef, GA, Fischer, AH (2020) Toward an integrative psychometric model of emotions. Perspectives on psychological science 15, 444468.

Lawrence, AB, Vigors, B, Sandöe, P (2019) What Is so Positive about Positive Animal Welfare? - Critical Review of the Literature. Animals 9, 783.

Lee, C, Colditz, IG, Campbell, DL (2018) A framework to assess the impact of new animal management technologies on welfare: A case study of virtual fencing. Frontiers in veterinary science $\mathbf{5}, 187$.

Lerner, H (2020) Health in Non-human Organisms. In 'Explaining Health Across the Sciences.' pp. 333-346. (Springer:

Llonch, P, Hoffmann, G, Bodas, R, Mirbach, D, Verwer, C, Haskell, M (2020) Opinion paper: Measuring livestock robustness and resilience: are we on the right track? Animal 14, 667-669.

López-Otín, C, Kroemer, G (2021) Hallmarks of health. Cell 184, 33-63. 
Lyon, P (2015) The cognitive cell: bacterial behavior reconsidered. Frontiers in Microbiology 6, 264.

Lyons, DM, Schatzberg, AF (2020) Resilience as a process instead of a trait. In 'Stress resilience.' (Ed. A Chen.) pp. 33-44. (Academic Press: London)

Madsen, M, van der Werf, J, Börner, V, Mulder, H, Clark, S (2021) Estimation of macroand micro-genetic environmental sensitivity in unbalanced datasets. Animal 15, 100411.

Mallard, BA, Emam, M, Paibomesai, M, Thompson-Crispi, K, Wagter-Lesperance, L (2015) Genetic selection of cattle for improved immunity and health. Japanese Journal of Veterinary Research 63, S37-S44.

Marıa, G, Escós, J, Alados, CL (2004) Complexity of behavioural sequences and their relation to stress conditions in chickens (Gallus gallus domesticus): a noninvasive technique to evaluate animal welfare. Applied Animal Behaviour Science 86, 93-104.

Mason, G, Walker, M, Duggan, G, Roulston, N, Van Slack, A (2012) Negative affective states and their effects on morbidity, mortality and longevity. Animal Welfare 21, 497-509.

Mattiello, S, Battini, M, De Rosa, G, Napolitano, F, Dwyer, C (2019) How Can We Assess Positive Welfare in Ruminants? Animals 9, 758.

Medzhitov, R (2021) The spectrum of inflammatory responses. Science 374, 1070-1075.

Mellor, D, Stafford, K (2001) Integrating practical, regulatory and ethical strategies for enhancing farm animal welfare. Australian Veterinary Journal 79, 762-768.

Mellor, DJ (2015) Enhancing animal welfare by creating opportunities for positive affective engagement. New Zealand Veterinary Journal 63, 3-8.

Mellor, DJ (2016) Updating animal welfare thinking: Moving beyond the "Five Freedoms" towards "a Life Worth Living”. Animals 6, 21.

Mellor, DJ (2017) Operational details of the five domains model and its key applications to the assessment and management of animal welfare. Animals 7, 60.

Mellor, DJ (2019) Preparing for Life After Birth: Introducing the Concepts of Intrauterine and Extrauterine Sensory Entrainment in Mammalian Young. Animals 9, 826.

Mellor, DJ, Beausoleil, NJ (2015) Extending the'Five Domains' model for animal welfare assessment to incorporate positive welfare states. Animal Welfare 24, 241-253.

Mendl, M, Burman, OHP, Paul, ES (2010) An integrative and functional framework for the study of animal emotion and mood. Proceedings of the Royal Society B: Biological Sciences 277, 2895-2904.

Mengistu, U, Puchala, R, Sahlu, T, Gipson, T, Dawson, L, Goetsch, A (2017) Conditions to evaluate differences among individual sheep and goats in resilience to high heat load index. Small Ruminant Research 147, 89-95.

Meyer, K, Colditz, IG (2015) Estimates of genetic parameters for seasonal weight changes of beef cows. Association for the Advancement of Animal Breeding and Genetics Proceedings21, 193-196.

Miller, J (1963) Origins of immunological competence. British medical bulletin 19, 214218.

Modell, H, Cliff, W, Michael, J, McFarland, J, Wenderoth, MP, Wright, A (2015) A physiologist's view of homeostasis. Advances in physiology education 39, 259266. 
Mulder, H, Rashidi, H (2017) Selection on resilience improves disease resistance and tolerance to infections. Journal of Animal Science 95, 3346-3358.

Neethirajan, S, Tuteja, SK, Huang, S-T, Kelton, D (2017) Recent advancement in biosensors technology for animal and livestock health management. Biosensors and Bioelectronics 98, 398-407.

Nguyen-Ba, H, van Milgen, J, Taghipoor, M (2020) A procedure to quantify the feed intake response of growing pigs to perturbations. Animal 14, 253-260.

Nordenfelt, L (2006) 'Animal and human health and welfare: a comparative philosophical analysis.' (CABI: Wallingford)

Nordenfelt, L (2011) Health and welfare in animals and humans. Acta Biotheoretica 59, 139-152.

Nunes Marsiglio Sarout, B, Waterhouse, A, Duthie, C-A, Candal Poli, CHE, Haskell, MJ, Berger, A, Umstatter, C (2018) Assessment of circadian rhythm of activity combined with random regression model as a novel approach to monitoring sheep in an extensive system. Applied Animal Behaviour Science 207, 26-38.

Poppe, M, Mulder, H, Kamphuis, C, Veerkamp, R (2021a) Between-herd variation in resilience and relations to herd performance. Journal of Dairy Science 104, 616627.

Poppe, M, Mulder, HA, Veerkamp, RF (2021b) Validation of resilience indicators by estimating genetic correlations among daughter groups and with yield responses to a heat wave and disturbances at herd level. Journal of Dairy Science 104, 80948106.

Poppe, M, Veerkamp, RF, Van Pelt, ML, Mulder, HA (2020) Exploration of variance, autocorrelation, and skewness of deviations from lactation curves as resilience indicators for breeding. Journal of Dairy Science 103, 1667-1684.

Putz, AM, Harding, J, Dyck, MK, Fortin, F, Plastow, GS, Dekkers, J (2019) Novel resilience phenotypes using feed intake data from a natural disease challenge model in wean-to-finish pigs. Frontiers in genetics 9, 660.

Pyrkov, TV, Avchaciov, K, Tarkhov, AE, Menshikov, LI, Gudkov, AV, Fedichev, PO (2021) Longitudinal analysis of blood markers reveals progressive loss of resilience and predicts human lifespan limit. Nature communications 12, 1-10.

Rault, JL, Hintze, S, Camerlink, I, Yee, J (2020) Positive welfare and the like: Distinct views and a proposed framework. Frontiers in veterinary science 7, 370.

Rauw, WM, Kanis, E, Noordhuizen-Stassen, EN, Grommers, FJ (1998) Undesirable side effects of selection for high production efficiency in farm animals, a review. Livestock Production Science 56, 15-33.

Réale, D, Reader, SM, Sol, D, McDougall, PT, Dingemanse, NJ (2007) Integrating animal temperament within ecology and evolution. Biological reviews 82, 291-318.

Refinetti, R, Wassmer, T, Basu, P, Cherukalady, R, Pandey, VK, Singaravel, M, Giannetto, C, Piccione, G (2016) Variability of behavioral chronotypes of 16 mammalian species under controlled conditions. Physiology \& Behavior 161, 53-59.

Reid, J, Nolan, A, Scott, M (2022) Application of Psychometrics to Assess Quality of Life in Animals. In 'Bridging Research Disciplines to Advance Animal Welfare Science: A practical guide.' (Ed. I Camerlink.) pp. 125-140. (CAB International: Wallingford) 
Reverter, A, Hine, BC, Porto-Neto, L, Li, Y, Duff, CJ, Dominik, S, Ingham, AB (2021) ImmuneDEX: a strategy for the genetic improvement of immune competence in Australian Angus cattle. Journal of Animal Science 99, skaa384.

Revilla, M, Friggens, NC, Broudiscou, LP, Lemonnier, G, Blanc, F, Ravon, L, Mercat, M-J, Billon, Y, Rogel-Gaillard, C, Le Floch, N (2019) Towards the quantitative characterisation of piglets' robustness to weaning: a modelling approach. Animal 13, 2536-2546.

Robbins, J, Franks, B, von Keyserlingk, MA (2018) 'More than a feeling': An empirical investigation of hedonistic accounts of animal welfare. Plos One 13, e0193864.

Romero, LM, Dickens, MJ, Cyr, NE (2009) The reactive scope model - a new model integrating homeostasis, allostasis, and stress. Hormones and Behavior 55, 375389.

Rowland, T, Pike, T, Burman, $O$ (2021) A network perspective on animal welfare. Animal Welfare 30, 235-248.

Russell, G, Kalafatakis, K, Lightman, S (2015) The importance of biological oscillators for hypothalamic - pituitary - adrenal activity and tissue glucocorticoid response: coordinating stress and neurobehavioural adaptation. Journal of neuroendocrinology 27, 378-388.

Russell, JA (2003) Core affect and the psychological construction of emotion. Psychological review 110, 145.

Ryff, CD, Boylan, JM, Kirsch, JA (2021) Eudaimonic and hedonic well-being: an integrative perspective with linkages to sociodemographic factors and health. In 'Measuring Well-Being.' pp. 92-135. (Oxford University Press:

Ryff, CD, Singer, BH, Dienberg Love, G (2004) Positive health: connecting well-being with biology. Philosophical Transactions of the Royal Society of London. Series B: Biological Sciences 359, 1383-1394.

Sánchez-Molano, E, Kapsona, VV, Oikonomou, S, McLaren, A, Lambe, N, Conington, J, Banos, G (2020) Breeding strategies for animal resilience to weather variation in meat sheep. BMC genetics 21, 1-11.

Sandgren, CH, Lindberg, A, Keeling, L (2009) Using a national dairy database to identify herds with poor welfare. Animal Welfare 18, 523-532.

Santana, M, Eler, J, Cardoso, F, Albuquerque, L, Ferraz, J (2013) Phenotypic plasticity of composite beef cattle performance using reaction norms model with unknown covariate. Animal 7, 202-210.

Satpute, AB, Kragel, PA, Barrett, LF, Wager, TD, Bianciardi, M (2019) Deconstructing arousal into wakeful, autonomic and affective varieties. Neuroscience Letters 693, 19-28.

Scheffer, M, Bolhuis, JE, Borsboom, D, Buchman, TG, Gijzel, SMW, Goulson, D, Kammenga, JE, Kemp, B, van de Leemput, IA, Levin, S (2018) Quantifying resilience of humans and other animals. Proceedings of the National Academy of Sciences 115, 11883-11890.

Scheibe, KM, Berger, A, Langbein, J, Streich, WJ, Eichhorn, K (1999) Comparative Analysis of Ultradian and Circadian Behavioural Rhythms for Diagnosis of Biorhythmic State of Animals. Biological Rhythm Research 30, 216-233.

Schillings, J, Bennett, R, Rose, DC (2021) Exploring the Potential of Precision Livestock Farming Technologies to Help Address Farm Animal Welfare. Frontiers in Animal Science 2, 
Schulkin, J, Sterling, P (2019) Allostasis: A Brain-Centered, Predictive Mode of Physiological Regulation. TRENDS in Neurosciences 42, 740-752.

Scott, EM, Nolan, AM, Fitzpatrick, JL (2001) Conceptual and methodological issues related to welfare assessment: a framework for measurement. Acta Agriculturae Scandinavica, Section A-Animal Science 51, 5-10.

Simms, EL (2000) Defining tolerance as a norm of reaction. Evolutionary Ecology 14, 563-570.

Spiga, F, Lightman, SL (2020) Rhythms of stress resilience. In 'Stress Resilience.' pp. 107-117. (Elsevier:

Špinka, M (2012) Social dimension of emotions and its implication for animal welfare. Applied Animal Behaviour Science 138, 170-181.

Spinka, M, Newberry, RC, Bekoff, M (2001) Mammalian play: training for the unexpected. The Quarterly review of biology 76, 141-168.

Spinka, MARE, Wemelsfelder, F (2011) Environmental challenge and animal agency. Animal Welfare.CABI International, Wallingford 27-43.

Steel, J (2003) Effects of protein supplementation of young sheep on resistance development and resilience to parasitic nematodes. Australian Journal of Experimental Agriculture 43, 1469-1476.

Sterling, P, Eyer, J (1988) Allostasis: a new paradigm to explain arousal pathology. In 'Handbook of Life Stress, Cognition and Health.' (Eds S Fisher, J Reason.) pp. 629649. (J. Wiley and Sons: New York)

Strandberg, E (2009) The role of environmental sensitivity and plasticity in breeding for robustness: lessons from evolutionary genetics. Breeding for robustness in cattle.EAAP Publication, Wageningen, the Netherlands 17-33.

Sun, D, Webb, L, Van Der Tol, R, Van Reenen, K (2021) A systematic review of automatic health monitoring in calves: glimpsing the future from current practice. Frontiers in veterinary science $\mathbf{8}$,

Tedeschi, LO, Muir, JP, Riley, DG, Fox, DG (2015) The role of ruminant animals in sustainable livestock intensification programs. International Journal of Sustainable Development \& World Ecology 22, 452-465.

Timiras, P (1996) Physiology of aging: standards for age-related functional competence. In 'Comprehensive human physiology.' pp. 2391-2405. (Springer:

Tsartsianidou, V, Kapsona, VV, Sánchez-Molano, E, Basdagianni, Z, Carabaño, MJ, Chatziplis, D, Arsenos, G, Triantafyllidis, A, Banos, G (2021) Understanding the seasonality of performance resilience to climate volatility in Mediterranean dairy sheep. Scientific Reports 11, 1-11.

Van Dixhoorn, I, de Mol, R, van der Werf, J, van Mourik, S, van Reenen, C (2018) Indicators of resilience during the transition period in dairy cows: A case study. Journal of Dairy Science 101, 10271-10282.

Veissier, I, Botreau, R, Perny, P (2009) Scoring animal welfare: difficulties and Welfare Quality ${ }^{\circledR}$ solutions. An Overview of the Development of the Welfare Quality Assessment Systems; Keeling, L., Ed 15-32.

von Borell, E, Langbein, J, Despr,s, G, Hansen, S, Leterrier, C, Marchant-Forde, J, Marchant-Forde, R, Minero, M, Mohr, E, Prunier, A, Valance, D, Veissier, I (2007) Heart rate variability as a measure of autonomic regulation of cardiac activity for assessing stress and welfare in farm animals - a review. Physiology \& Behavior 92, 293-316. 
von Keyserlingk, MAG, Barrientos, A, Ito, K, Galo, E, Weary, DM (2012) Benchmarking cow comfort on North American freestall dairies: Lameness, leg injuries, lying time, facility design, and management for high-producing Holstein dairy cows. Journal of Dairy Science 95, 7399-7408.

Waddington, $\mathrm{CH}$ (1942) Canalization of development and the inheritance of acquired characters. Nature 150, 563-565.

Waddington, $\mathrm{CH}$ (1957) 'The strategy of the genes.' (Routledge: London)

Waiblinger, S, Boivin, X, Pedersen, V, Tosi, M-V, Janczak, AM, Visser, EK, Jones, RB (2006) Assessing the human-animal relationship in farmed species: a critical review. Applied Animal Behaviour Science 101, 185-242.

Weary, D, Robbins, J (2019) Understanding the multiple conceptions of animal welfare. Anim. Welf 28, 33-40.

Webb, LE, Veenhoven, RR, Harfeld, JLJL, Jensen, MB (2018) What is animal happiness? Annals of the New York Academy of Sciences 1438, 62-76.

Webster, J (2016) Animal Welfare: Freedoms, Dominions and "A Life Worth Living". Animals 6, 35.

White, RW (1959) Motivation reconsidered: The concept of competence. Psychological review 66, 297.

Wilkie, B, Mallard, B (1999) Selection for high immune response: an alternative approach to animal health maintenance? Veterinary Immunology and Immunopathology 72, 231-235.

Williams, AF, Boles, JA, Herrygers, MR, Berardinelli, JG, Meyers, MC, Thomson, JM (2019) Blood lactate and rectal temperature can predict exit velocity of beef feedlot steers. Translational Animal Science 3, 1530-1542.

Williams, LA (2021) From Human Wellbeing to Animal Welfare. Neuroscience \& Biobehavioral Reviews 131, 941-952.

Wilson, PN, Osbourn, DF (1960) Compensatory growth after undernutrition in mammals and birds. Biological reviews 35, 324-361.

Ye, J, Medzhitov, R (2019) Control strategies in systemic metabolism. Nature Metabolism 1, 947-957.

Yeates, JW, Main, DCJ (2008) Assessment of positive welfare: a review. The Veterinary Journal 175, 293-300. 